\title{
Causes of Mortality of Northern Sea Otters (Enhydra lutris kenyoni) in Alaska From 2002 to 2012
}

\author{
Kathleen Ann Burek Huntington ${ }^{1 *}$, Verena Ann Gill ${ }^{2,3}$, Amanda M. Berrian ${ }^{4}$, \\ Tracey Goldstein ${ }^{5}$, Pam Tuomi ${ }^{6}$, Barbara A. Byrne ${ }^{7}$, Kristin Worman ${ }^{3}$ and Jonna Mazet ${ }^{5}$ \\ ${ }^{1}$ Alaska Veterinary Pathology Services, Eagle River, AK, United States, ${ }^{2}$ NOAA Fisheries, Anchorage, AK, United States, \\ ${ }^{3}$ U.S. Fish \& Wildlife Service, Anchorage, AK, United States, ${ }^{4}$ Department of Veterinary Preventive Medicine, The Ohio State \\ University, Columbus, $\mathrm{OH}$, United States, ${ }^{5}$ Karen C. Draver Wildlife Health Center, One Health Institute, University \\ of California, Davis, Davis, CA, United States, ${ }^{6}$ Alaska SeaLife Center, Seward, AK, United States, ${ }^{7}$ Department of \\ Pathology, Microbiology, and Immunology, School of Veterinary Medicine, University of California, Davis, Davis, CA, \\ United States
}

\section{OPEN ACCESS}

Edited by:

Alvin Cyril Camus,

University of Georgia, United States

Reviewed by:

William George Van Bonn,

Shedd Aquarium, United States Kathleen Colegrove,

University of Illinois at

Urbana-Champaign, United States

*Correspondence:

Kathleen Ann Burek Huntington avps.kbh@gmail.com

Specialty section: This article was submitted to

Marine Megafauna,

a section of the journal

Frontiers in Marine Science

Received: 17 November 2020

Accepted: 26 January 2021

Published: 26 February 2021

Citation:

Burek Huntington KA, Gill VA, Berrian AM, Goldstein T, Tuomi P, Byrne BA, Worman $K$ and Mazet $J$

(2021) Causes of Mortality of Northern Sea Otters (Enhydra lutris kenyoni) in Alaska From 2002 to 2012. Front. Mar. Sci. 8:630582. doi: 10.3389/fmars.2021.630582
Most of the world's sea otters reside in Alaska, but there has never been an assessment of long-term mortality patterns for this keystone predator. We examined data collected from 780 northern sea otter (Enhydra lutris kenyoni) carcasses recovered in Alaska from 2002 to 2012 to evaluate the causes of mortality and risk factors associated with death. A smaller group ( $n=144,18 \%$ ) of fresh non-frozen carcasses were included in a more detailed mortality analysis. Forty-four\% of the fresh dead otters were determined to have died from infectious endocarditis, meningoencephalitis, and/or septicemia due to systemic streptococcosis ("Strep syndrome"). Streptococcus lutetiensis, a member of the Streptococcus bovis/equinus (SB/E) group was most commonly isolated, although other members of the SB/E group were identified. There were fewer cases where S. phocae and other streptococci were isolated. A regression analysis revealed age and location risk factors for Strep syndrome. Subadults were the highest risk age group, and otters recovered from the Kachemak Bay region were 3.6 times (95\% Cl: 2.2-5.9) more likely to die from Strep syndrome than otters recovered elsewhere. Diagnosis of this Strep syndrome had not been reported in other marine mammals in Alaska. Sporadic cases of septicemia and infectious endocarditis due to S. lutetiensis have been seen in the southern sea otter population in California. Other causes of death for the fresh otters included neurologic diseases (10\%), trauma (8\%), nutritional diseases (7\%), cardiovascular diseases (7\%), gastrointestinal diseases /parasites (6\%), undetermined (5\%), septicemia (3\%), and neoplasia (3\%). All other causes of death (oiling, hepatobiliary, fungal, marine biotoxins, pulmonary) were at or below $1 \%$. Twenty percent of fresh animals were positive for phocine distemper virus (PDV) by polymerase chain reaction (PCR, 11/55), 18\% seropositive for PDV (7/38), and paramyxovirus-like particles were demonstrated by electron microscopy within inclusion bodies from one animal. Low concentrations of the harmful algal bloom toxins domoic acid and saxitoxin were also detected in $26 \%$ and $22 \%$ of fresh animals, respectively. Protozoal disease was rare. These patterns of disease differ from sea otters in other regions and possible reasons are discussed.

Keywords: northern sea otter, Enhydra lutris kenyoni, Alaska, stranding, mortality, Strep syndrome, Streptococcus lutetiensis, phocine distemper virus 


\section{INTRODUCTION}

Data from marine mammal stranding programs have been used to understand causes of mortality (Kreuder et al., 2003; Joly et al., 2009; Bogomolni et al., 2010; Bossart, 2011) and types of human interactions (Goldstein et al., 1999) and have led to the discovery of novel diseases (Carrasco et al., 2014b; Shen et al., 2017; Siqueira et al., 2017). As sea otters share the coastal environment with humans and consume some of the same foods, they can serve as effective sentinels for public health issues in a rapidly changing world (Bossart, 2011). Data from stranded sea otters have aided in the documentation of anthropogenic drivers of infectious diseases, such as land-based freshwater runoff as a source of Toxoplasma gondii and Capillaria hepatica infection in southern sea otters (Enhydra lutris nereis; Miller et al., 2002a; VanWormer et al., 2016; Miller et al., 2020). Changes in infectious diseases in sea otters may also correlate with climate change parameters, such as increased sea surface temperatures along with increases in Vibrio parahaemolyticus infections (Goertz et al., 2013) and expansion of the distribution of phocine distemper virus associated with reductions in sea ice (VanWormer et al., 2019).

In Alaska, a northern sea otter (Enhydra lutris kenyoni) stranding program was initiated in 2002 by the U.S. Fish and Wildlife Service (USFWS) to examine causes of strandings and mortality in the three Alaska sea otter population stocks (Figure 1); Southwest (SW), Southcentral (SC), and Southeast (SE) (Gorbics and Bodkin, 2001). In 2005, following a population decline of more than $50 \%$ since the mid-1980s, the SW stock of northern sea otters was listed as threatened under the U.S. Endangered Species Act (ESA). Although the SC and SE stocks are not listed under the ESA, an observed increase in the number of sea otter carcasses being recovered from the SC stock in Kachemak Bay with mortality due to high proportions of infectious endocarditis (IE) resulted in a Marine Mammal Unusual Mortality Event (UME) being declared by the U.S. Working Group on UMEs in 2006.

Prior studies examining the health and disease of northern sea otters in Alaska have been limited in their timeline and scope, with most examining the effects of the 1989 Exxon Valdez oil spill in Prince William Sound which found that environmental disasters can have long-term impacts on survival rates and mortality (Bodkin et al., 2000; Monson et al., 2000; Ballachey et al., 2003; Miles et al., 2012). Other studies have compared northern sea otters in Alaska to southern sea otters in California, showing low exposure to most potential marine and terrestrial pathogens tested but $40 \%$ exposure to PDV (Hanni et al., 2003; Goldstein et al., 2011; Hoyt et al., 2014); however, characterization of morbidity and mortality had not been previously done. Many long-term studies in southern sea otters have led to a greater understanding of the causes of the lack of population recovery, factors involved in human interactions, resource limitations, infectious diseases, and toxins, with potential mitigation strategies (Miller et al., 2010a; Miller et al., 2010b; Thometz et al., 2014; Chinn et al., 2016). A longterm, systematic evaluation of the causes of death of northern sea otters in Alaska was needed to assess the possible role of disease in the decline of the threatened SW population stock. The objective of this study was to examine the causes of mortality in northern sea otters recovered in Alaska from 2002 to 2012, using stranding data to evaluate risk factors associated with mortality. Such detailed evaluation of mortality patterns may have implications for the management of the species, as well as the potential to broaden our understanding of the health of the nearshore ecosystem in Alaska in relation to possible climate change factors and threats to human health.

Here we present the results of examinations of northern sea otter carcasses, divided into two groups. The "larger group" $(n=780)$ includes all animals reported and examined from 2002 to 2102. The "smaller group" $(n=144)$ includes the subset of fresh, non-frozen animals for which a formal necropsy, histopathology and ancillary testing was conducted. The larger group provides broader demographic information as well as wider geographical representation. The smaller group offers greater detail on COD determination. Together, both groups provide insight into patterns of sea otter mortality across Alaska.

\section{MATERIALS AND METHODS}

\section{Animals and Sampling}

In 2002, the USFWS began a concerted effort to collect, examine, and sample as many Northern sea otter carcasses as possible through a community-based, volunteer marine mammals stranding network in collaboration with the Alaska SeaLife Center (ASLC) and National Oceanic and Atmospheric Administration (NOAA) Fisheries. A Microsoft Access database for all cases and related information was developed and maintained by USFWS.

Carcasses, from dead-stranded sea otters and live-stranded animals that subsequently died or were euthanized, recovered between 2002 and 2012 were included in this analysis. Carcasses were recovered from across more than 1,500 miles of Alaska shoreline and extended from Tanaga Island in the central end of the Aleutians (SW stock) to Kuiu Island in the Alexander Archipelago (SE stock; Figure 1). Stranding locations were determined at the time of recovery by GPS on-site or by estimation from Google Earth ${ }^{\mathrm{TM}}$ (Google Inc., Mountain View, CA) if GPS location was unavailable. Additional data upon recovery included date, time, weather, and any visible signs of injury.

Carcass condition was assessed, including estimated postmortem interval classification $(<$ or $>48 \mathrm{~h}$ ) and extent of decomposition. If post-mortem interval exceeded 48 -h, or a fresh carcass could not be shipped immediately, the specimen was frozen for later necropsy; if less than $48 \mathrm{~h}$, it was transported to the USFWS in Anchorage, AK or the ASLC in Seward, AK for immediate necropsy. Due to the large and remote areas where carcasses were reported and recovered, some fresh dead carcasses could not be shipped within the 48-h time frame and were subsequently frozen for later necropsy. Each necropsy was performed by a veterinarian with expertise in marine mammal medicine and/or a board-certified veterinary pathologist. 


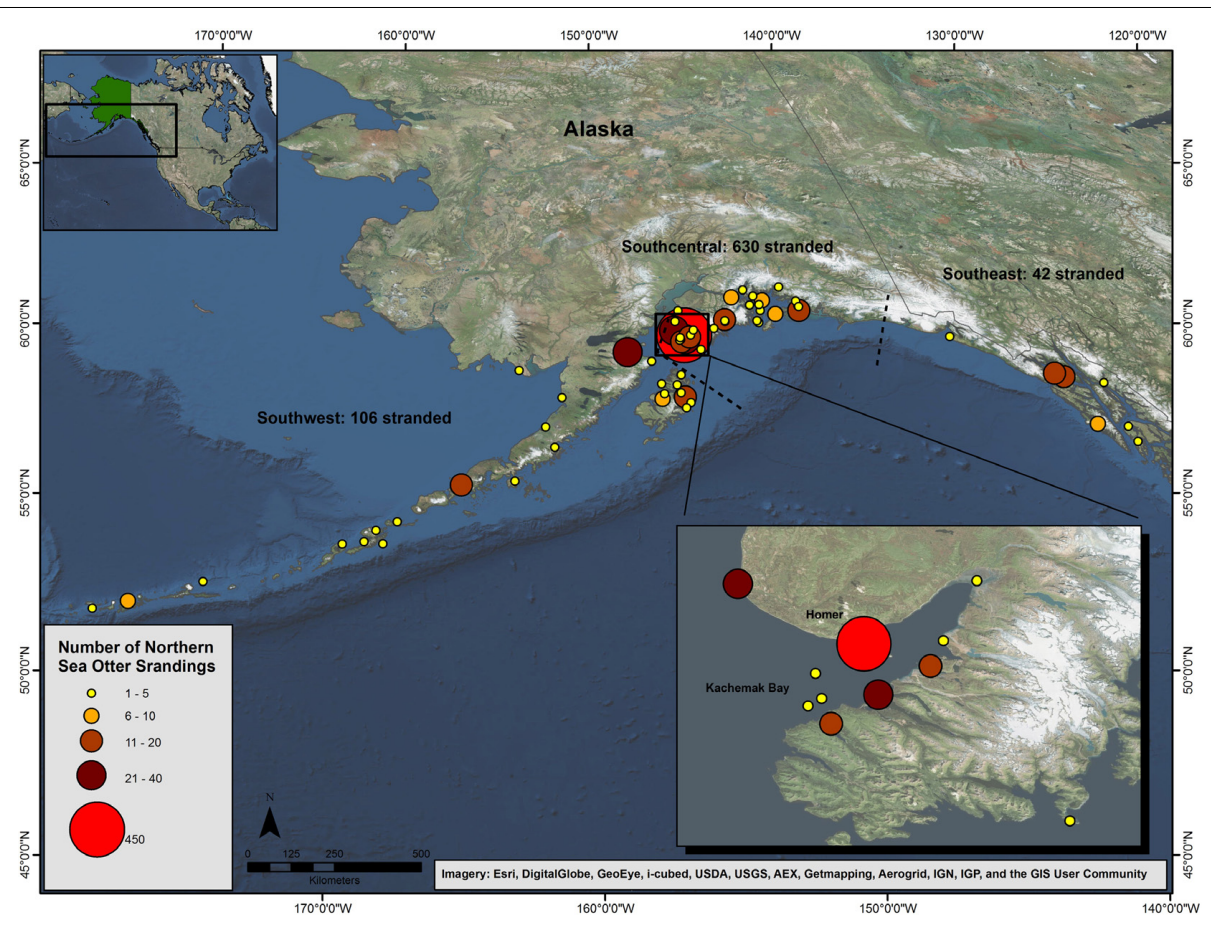

FIGURE 1 | Distribution of northern sea otter (Enhydra lutris kenyoni) carcasses recovered in Alaska from 2002 to 2012 ( $n=778$ ). The dashed lines show the stock delineations.

Data collected on carcasses included carcass condition, age class, nutritional state, and sex. Classification of carcass condition was based on gross appearance and included fresh, mild, moderate or advanced decomposition, or skeletal/mummified (Dierauf and Gulland, 2001). Age class (von Biela et al., 2009) was estimated as aged adult ( $>10$ years), adult (3-10 years, female; 4-10 years, male), subadult (1-2 years, female; $1-3$ years, male), or pup ( $<1$ year), and was determined using tooth wear and body size (Kreuder et al., 2003). When present, a first premolar was extracted and submitted to Matson's Laboratory (Milltown, MT) for accurate aging. Nutritional state was classified as fat, normal, thin, or emaciated as determined by available body fat in the subcutaneous space, groin, mesentery, and/or kidney lobules (Dierauf and Gulland, 2001). Sex was determined based on gross visual examination; for skeletal remains, the animal was cataloged as male if a baculum was present. Examination also included morphometrics: weight (kgs), xiphoid girth $(\mathrm{cm})$, right forepaw width $(\mathrm{cm})$, straight length $(\mathrm{cm})$, skull length $(\mathrm{cm})$, and skull width $(\mathrm{cm})$.

Carcasses were classified as belonging to one of the three population stocks in Alaska: SE, SC, and SW. The geographic location for each carcass was mapped using ArcGIS (version 10.1, ESRI, Redlands, CA, United States) for all recovered carcasses with known or estimated geographic locations (latitude/longitude).

\section{Diagnostics}

Carcass condition and histologic findings guided the extent of examination and biologic samples collected and tested. As the program progressed over a decade, the number and type of samples and tests were refined due to logistics and costs. Fresh dead carcasses received the most complete diagnostic workup including, but not limited to, morphometric measurements; gross necropsy; radiographs; full histopathologic examination; and screening for three protozoal agents (Toxoplasma gondii, Sarcocystis neospora and Neospora caninum), bacterial systemic and fecal pathogens, phocine distemper virus, and harmful algal bloom toxins (domoic acid and saxitoxin) testing.

\section{Histopathology}

Tissues collected for histopathologic examination were placed in $10 \%$ neutral buffered formalin (NBF) in a 10:1 ratio of NBF:tissue. Tissues were paraffin-embedded, sectioned (5 $\mu \mathrm{m})$ and stained with hematoxylin and eosin (H\&E) at Histology Consultation Services, Inc. (HCS Everson, WA). Special stains including Periodic Acid-Schiff (PAS) for fungi and glycoprotein, Gram stain and silver stain were performed as needed.

\section{Bacteriology}

Carcasses in good condition (fresh or mild decomposition) were sampled to culture for bacterial pathogens. Amies swabs were collected from whole blood, stomach wall, tonsil, and tissues including cerebrum, heart valves, mesenteric lymph node, and where gross lesions were suggestive of a bacterial etiology. Gastrointestinal swabs with Cary Blair transport medium (VWR) or loops of jejunum and colon were used to culture for fecal pathogens. Specimens were shipped with frozen gel packs overnight to the University of California, Davis School of Veterinary Medical Teaching Hospital Microbiology 
Lab (Davis, CA, United States) for pathogen screening. For Salmonella, gastrointestinal samples were inoculated into selenite broth (Veterinary Medicine Biological Media Services, Davis, $\mathrm{CA}$, United States) and subcultured after $18 \mathrm{~h}$. incubation at $35^{\circ} \mathrm{C}$ on xylose-lysine-tergitol-4 agar (Hardy Diagnostics, Santa Maria, CA, United States). Screening for Vibrio spp. utilized alkaline peptone broth (Hardy Diagnostics) for enrichment at $35^{\circ} \mathrm{C}$, incubation overnight and subculture to TCBS agar (Hardy Diagnostics) with incubation at $35^{\circ} \mathrm{C}$. For Campylobacter isolation, gastrointestinal samples were inoculated on Campy CVA agar (Hardy Diagnostics) and incubated at $35^{\circ} \mathrm{C}$ under microaerophilic conditions. Culture of gastrointestinal tissues for SB/E utilized Rose agar (Hardy Diagnostics) incubated at $35^{\circ} \mathrm{C}$ in $5 \% \mathrm{CO} 2$. Tissue samples were inoculated onto tryptic soy agar with $5 \%$ sheep blood (Hardy Diagnostics, Santa Maria, CA, United States). The plates were incubated at $35^{\circ} \mathrm{C}$ in a $5 \%$ $\mathrm{CO}_{2}$-enriched atmosphere for a minimum of 5 days. Bacterial identification was accomplished using standard microbiological algorithms including Gram staining, tubed media, and strip identification (Spellerberg and Brandt, 2011). In certain cases, some bacteria (i.e., $\mathrm{SB} / \mathrm{E}$ and Vibrio spp.) were sent to the Centers for Disease Control and Prevention (Atlanta, GA) and the Alaska State Public Health Laboratory (Anchorage, AK) for further typing (Counihan-Edgar et al., 2012; Goertz et al., 2013).

\section{Morbillivirus}

Morbillivirus (canine and phocine distemper; CDV and PDV) serology was conducted at the Oklahoma Animal Disease Diagnostic Laboratory (Stillwater, OK, United States) or the Marine Ecosystem Health Diagnostic and Surveillance Lab (Davis, CA, United States). Serum was aseptically collected and tested by serum neutralization with titers greater than 32 considered positive (Goldstein et al., 2009). Tissues for morbillivirus screening were stored at $-80^{\circ} \mathrm{C}$; and reverse transcription polymerase chain reaction (RT-PCR) was performed on cerebrum, lung, and hilar lymph node (Barrett et al., 1993).

\section{Protozoa}

Testing for Toxoplasma gondii, Sarcocystis neurona, and Neospora caninum was performed by culture, PCR, serology, and direct visualization of intralesional protozoal cysts on histopathology with some confirmation by immunohistochemistry (IHC). Specimens were submitted to the Conrad Protozoal Laboratory at the UC Davis School of Veterinary Medicine, Davis, CA, United States. Serum and/or cerebrospinal fluid (CSF) were aseptically collected and screened by immunofluorescence (Miller et al., 2002b), and, when indicated, culture and/or PCR were performed on $1 \mathrm{~cm}^{3}$ sections of cerebrum and cerebellum. Titers $\geq 40$ were considered positive and $>320$ on the serological immunofluorescent antibody test (IFAT) were considered supportive of infection by protozoal organisms. Antibody titers alone were not used to make a diagnosis based on their inability to distinguish between past and active infection. For the PCR, DNA was extracted from sea otter brain using the DNeasy Tissue Kit (Qiagen) and screened for the presence of
T. gondii, S. neurona, and N. caninum using $18 \mathrm{~S}$ rDNA panspecific primers as previously described (Miller et al., 2004).

\section{Marine Biotoxins}

Urine, feces, stomach contents, pericardial fluid, pleural fluid, and intestinal content were collected for domoic acid (DA) and/or saxitoxin (STX) analysis and stored at $-80^{\circ} \mathrm{C}$. Samples were tested at the Northwest Fisheries Science Center's Wildlife Algal-Toxin Research and Response Network (WARRN-West) laboratory (Seattle, WA, United States), the California Animal Health and Food Safety Laboratory System (CAHFS), and the Alaska State Environmental Health Laboratory (AK EHL). At WARRN-West, samples were analyzed by Abraxis ELISA for saxitoxin and Biosense ${ }^{\circledR}$ DA ELISA for DA (Lefebvre (Lefebvre et al., 2016). At CAHFS and EHL, samples were tested for DA and STX by liquid chromatography-tandem mass spectrometry (LC/MS/MS) with a method detection limit of $5 \mathrm{ppb}$ (Tor et al., 2003; Diener et al., 2007).

\section{Cause of Death (COD)}

Causes of death (COD) were standardized so that the COD identified for each otter was the most substantial injury or disease process thought to initiate the sequence of events leading directly to death or "proximate COD." Contributing factors were assigned if pathologic conditions were identified that contributed to the probability of death but were not part of the primary disease complex (Kreuder et al., 2003). Carcasses were assigned no more than two contributing factors. Records were reviewed by a designated group of veterinary pathologists, veterinarians, and biologists to verify continuity in the application of assigned mortality categories. COD was based on gross findings and, when possible, histopathology and ancillary testing. A case definition for "Strep syndrome" was developed and assigned when COD was due to bacterial meningoencephalitis (ME), infectious endocarditis (IE), and/or septicemia due to a Streptococcus. Strep syndrome was confirmed when Streptococcus was isolated and there was corresponding pathology, or recorded as suspect when cases had gross and histologic findings that were consistent, but culture was not performed. For percentages of COD in the larger group, both suspect and confirmed cases of Strep syndrome were tabulated together since these CODs were based primarily on gross findings; for the smaller group, only confirmed Strep syndrome was tabulated in order to follow the most conservative approach.

When possible, causes of mortality and contributory factors were classified into associated groups: (1) Strep syndrome; (2) trauma including intraspecific wounds (fighting, mating induced), human interaction (boat strike, gunshot), predation, or unknown; (3) neurologic including encephalitis (not attributed to Strep syndrome), cerebral edema, hydrocephalus, porencephaly, or a primary seizure disorder; (4) cardiovascular including IE (not attributed to confirmed Strep syndrome), dilated cardiomyopathy (DCM), myocarditis, atherosclerosis, thromboembolic disease, heart failure (acute or chronic), endocardiosis, or an acute vascular event such as ischemic stroke or aneurysm; (5) nutrition if the carcass had depleted fat stores and/or histopathologic evidence of emaciation and in 
pups when the cause of death was confirmed hypoglycemia or presumed hypothermia (presumed abandoned); (6) gastrointestinal/parasitic including acanthocephalan enteritis, esophageal and intestinal impaction, intussusception, intestinal volvulus, enterocolitis, peritonitis, or gastric ulceration; (7) septicemia not caused by streptococci based on culture of organisms from multiple organs or histopathology of suppurative inflammations from multiple sites; (8) neoplasia; (9) harmful algal bloom (HAB) toxicosis when pathologic findings were consistent with exposure (i.e., consistent hippocampal changes) and when samples had unusually high concentrations of a biotoxin; (10) pulmonary including severe edema, pneumonia, drowning, marked pulmonary congestion with no other COD; (11) oiling; (12) hepatobiliary including jaundice, hepatic necrosis, and hepatitis; (13) systemic fungal infection; (14) urinary including urinary bladder obstruction or perforation; (15) musculoskeletal including osteomyelitis, arthritis, or other non-traumatic musculoskeletal conditions; and (16) reproductive including abortion and penile hematoma. In the larger group, COD was primarily based on gross findings with selected ancillary analysis based on carcass quality. As a result, these CODs tended to be those more readily diagnosed (i.e., trauma and IE). Despite these disadvantages, these data were of value to this study due to the vast amounts of temporal, and spatial, demographic information it included due to the large sample size. In particular, the larger group provided data on mortality in the threatened SW population where obtaining carcasses fresh enough for the full work up is all but impossible due to the remoteness of the region. The smaller group allowed for a more robust and consistent testing strategy and detailed mortality analysis. The full workup completed on the 144 fresh animals was the gold standard, but it was expensive, time and labor intensive, and took a program with staff dedicated to that project alone. With the frequency of sea otter carcasses recovered in Alaska, budgets becoming ever increasingly pinched, and management priorities shifting, that gold standard is not sustainable going into the future. So in order to compare sea otter patterns of mortality over time the larger group of animals in this study will provide a baseline for future work when a gross necropsy may be the only tool available.

\section{Statistical Analysis}

All carcasses, fresh and non-fresh, recovered between 2002 and 2012 were included in the demographic analysis which included a summary of age class, sex, nutritional state, carcass condition, and date and location of recovery. A two-sided chi-square test of independence was used to examine differences within sex, age class, and date of recovery. Due to a small sample size, fetal animals were combined with pups for statistical analysis.

When possible, causes of mortality were identified and included all stages of decomposition in the larger group $(n=780)$. Proportionate mortality ratios were calculated to identify the leading COD for these otters. A more detailed mortality analysis was performed on a smaller subset of carcasses $(n=144$; those that were recovered fresh, and included histopathology and ancillary diagnostics) and included the distribution of the COD by sex and age classes and the evaluation of these factors by the two-sided chi-square test of independence. For dichotomous distributions with an expected frequency less than five, the Fisher exact test (Fisher, 1935) was calculated. When appropriate, the strength of association was estimated by the odds ratio with a 95\% confidence interval. Logistic regression was used to identify risk factors for the leading causes of mortality. Covariates were sex, age class, and location. All statistical analyses were performed in SAS 9.3 (SAS Institute, Cary, NC, United States). A p-value $<0.05$ was considered statistically significant.

\section{RESULTS}

\section{Demographics}

From 2002 to 2012, 780 northern sea otter carcasses were obtained and included in the demographic analysis. Of these, 6\% $(\mathrm{n}=50)$ stranded alive but subsequently died or were humanely euthanized. Condition was recorded for 93\% $(n=727)$ of the carcasses. Whole carcasses in varied stages of decomposition made up most of the carcasses ( $n=617,85 \%)$, followed by skeletal remains $(n=109,15 \%)$. There was one carcass for which only the pelt remained. Of the whole carcasses, $44 \%(n=270)$ were classified as fresh; $27 \%(n=165)$ were moderately decomposed; and $29 \%(n=182)$ were in a state of advanced decomposition.

Sex was determined for $87 \%$ (675) of animals, of which $66 \%$ were male. The disproportionate recovery rate of males did not vary significantly between years (two-sided chi-square test, $p=0.3427)$. Age class was estimated for $96 \%(n=747)$ of carcasses and included 19\% $(n=145)$ aged adults, 34\% ( $n=257)$ adults, $21 \%(n=158)$ subadults, $24 \%(n=181)$ pups, and $0.8 \%(n=6)$ fetuses. More adult carcasses were recovered compared with all other age classes throughout the time period with the exception of 2010 when aged adults, subadults, and pups each outnumbered adult carcasses (two-sided chi-square test, $p=0.0151)$. Estimated age classes for females $(n=228)$ were $20 \%$ aged adults, $28 \%$ adults, $18 \%$ subadults, $33 \%$ pups, and $0.4 \%$ fetuses; males ( $n=447$ ) were $18 \%$ aged adults, $35 \%$ adults, $24 \%$ subadults, $21 \%$ pups, and $0.7 \%$ fetuses (Table 1). Age distribution varied significantly by sex (two-sided chi-square test, $p=0.0061$ ), as female carcasses were most likely to be pups and male carcasses were most likely to be adults.

Seventy-three percent $(570 / 780)$ of carcasses were classified according to nutritional state: $37 \%(n=210)$ were considered normal, $34 \%(n=193)$ were classified as thin, $17 \%(n=95)$ were emaciated, and $13 \%(n=72)$ were considered fat. Nutritional state did not vary significantly by sex (two-sided chi-square test, $p=0.5126$ ), but there was a significant association with age (two-sided chi-square test, $p=0.01$ ). Recovered subadults were most likely to be classified as thin; whereas for the other age categories, normal-weight animals were the most common classification. Underweight animals (classified as "thin" or "emaciated") were 1.7 times more likely to be subadults than adults $(95 \% \mathrm{CI}=1.1-2.6)$.

Animal recovery date was recorded for all but one mortality. Average annual recovery was 71 carcasses $(S D=33.4)$; from 2006 to 2010 reported mortalities exceeded the average recovery rate $(105,108,106,97$, and 87 carcasses, respectively). The 
TABLE 1 | Northern sea otter (Enhydra lutris kenyoni) carcasses by location (Kachemak Bay vs. all other locations) and cause of death (Strep syndrome vs. all other causes) by age class in Alaska from 2002 to 2012.

\begin{tabular}{|c|c|c|c|c|c|c|c|c|c|c|c|c|c|c|c|c|c|c|c|c|c|c|}
\hline \multirow{3}{*}{$\begin{array}{l}\text { Location } \\
\text { Cause of death }\end{array}$} & \multicolumn{18}{|c|}{ Age class } & & & & \\
\hline & \multicolumn{3}{|c|}{ Aged adult } & \multicolumn{3}{|c|}{ Adult } & \multicolumn{3}{|c|}{ Sub adult } & \multicolumn{3}{|c|}{ Pup } & \multicolumn{3}{|c|}{ Fetus } & \multicolumn{3}{|c|}{ Unknown } & \multicolumn{3}{|c|}{ Total } & \multirow[b]{2}{*}{ Total } \\
\hline & $\mathbf{M}$ & $\mathbf{F}$ & $\mathbf{U}$ & $\mathbf{M}$ & $\mathbf{F}$ & $\mathbf{U}$ & $\mathbf{M}$ & $\mathbf{F}$ & $\mathbf{U}$ & $\mathbf{M}$ & $\mathbf{F}$ & $\mathbf{U}$ & $\mathbf{M}$ & $\mathbf{F}$ & $\mathbf{U}$ & $\mathbf{M}$ & $\mathbf{F}$ & $\mathbf{U}$ & $\mathbf{M}$ & $\mathbf{F}$ & $\mathbf{U}$ & \\
\hline Kachemak Bay & & & & & & & & & & & & & & & & & & & & & & 546 \\
\hline Strep syndrome & 19 & 11 & 0 & 45 & 9 & 1 & 42 & 11 & 0 & 4 & 3 & 0 & 0 & 0 & 0 & 0 & 0 & 0 & 110 & 34 & 1 & 145 \\
\hline All other causes & 47 & 16 & 6 & 72 & 33 & 16 & 33 & 21 & 7 & 62 & 57 & 8 & 3 & 0 & 2 & 5 & 1 & 12 & 222 & 128 & 51 & 401 \\
\hline All other locations & & & & & & & & & & & & & & & & & & & & & & 232 \\
\hline Strep syndrome & 1 & 2 & 0 & 6 & 3 & 0 & 4 & 2 & 0 & 2 & 1 & 0 & 0 & 0 & 0 & 0 & 0 & 0 & 13 & 8 & 0 & 21 \\
\hline All other causes & 15 & 17 & 11 & 34 & 19 & 19 & 26 & 7 & 5 & 24 & 13 & 6 & 0 & 1 & 0 & 2 & 1 & 11 & 101 & 58 & 52 & 211 \\
\hline Total & 82 & 46 & 17 & 157 & 64 & 36 & 105 & 41 & 12 & 92 & 74 & 14 & 3 & 1 & 2 & 7 & 2 & 23 & 446 & 228 & 104 & $778^{\dagger}$ \\
\hline
\end{tabular}

$M$, male; F, female; U, unknown.

${ }^{\dagger}$ Recovery location was unavailable for two carcasses.

distribution by month showed that two-thirds of all reported mortalities were recovered from April to August, months which coincided with increased shoreline activity and search effort in Alaska. Specific stranding location was recorded for over $99 \%$ (778/780) of carcasses and occurred throughout the range from Tanaga Island in the central end of the Aleutians (SW stock) to Kuiu Island in the Alexander Archipelago (SE stock). The highest number of carcasses were recovered in the SC population stock (630/778), followed by the SW (106/778) and SE (42/778; Figure 1). Of those recovered in SC, $87 \%$ were located in Kachemak Bay (Figure 1, inset) which may have been in part due to increased search and recovery efforts by the robust stranding network in that area as well as a relatively recent exponential increase in that otter population (Gill et al., 2009). Overall, the Kachemak Bay region accounted for 70\% (547/778) of all reported mortalities for which locations were recorded. Due to the high proportion of carcasses from the Kachemak Bay region, statistical analyses were stratified by location (Kachemak Bay vs. all other locations) to determine whether geographic differences existed. Carcass condition did vary by region; $9 \%$ of carcasses from the Kachemak Bay region consisted of skeletal remains compared with $27 \%$ of carcasses from all other locations (twosided chi-square test, $p<0.0001)$. Because carcasses consisting only of skeletal remains were less likely to have accurate data for sex, age class, and nutritional state, only whole carcasses were stratified by location to determine geographic differences for these parameters. Nutritional state, sex, and age class were not significantly associated with stranding region (two-sided chisquare tests, $p=0.06, p=0.6669, p=0.9039$, respectively).

\section{Causes of Death (COD)}

In the larger group ( $n=780)$, a COD could be determined for $62 \%(n=483)$ of carcasses (Figure 2A). The most common causes were confirmed or suspected Strep syndrome $(n=166$, $21 \%)$, trauma $(n=128,16 \%)$, nutritional $(n=37,5 \%)$, and cardiovascular $(n=36,5 \%)$. Causes of death in the larger group not represented in the smaller group included reproductive $(n=7,1 \%)$ due to abortion $(n=4)$, dystocia $(n=1)$, and penile hematoma $(n=1)$, neonatal mortality $(n=1)$ and urinary due to urinary bladder perforation and obstruction $(n=6,1 \%)$.

The most common COD, Strep syndrome, was further categorized by sex, age class, and location to determine demographic and spatial trends (Table 1). Strep syndrome did not vary significantly by sex (two-sided chi-square test, $p=0.2416$ ); however, cases did vary significantly by age and location of recovery (two-sided chi-square test, $p<0.0001$ for both variables). A logistic regression analysis evaluated Strep syndrome vs. all other causes of death and revealed that otters recovered from the Kachemak Bay region were 3.6 times (95\% CI: 2.2-5.9) more likely to die from Strep syndrome than otters recovered elsewhere. Subadults were the highest risk age group; odds of Strep syndrome in this age group were approximately twice that of adults (95\% CI: $1.2-2.8$ ) and aged adults (95\% CI: 1.2-3.4) and more than 10 times (95\% CI: 5.1-21.4) higher than juveniles. Age and sex were not significant predictors for the remaining CODs including neurologic, cardiovascular disease, nutritional, gastrointestinal/parasitic disease, non-Streptococcal septicemia and neoplasia, HAB toxicosis, oiling, and pulmonary.

The smaller group, which represents fresh dead carcasses that were not frozen prior to necropsy with complete histopathologic analysis and ancillaries $(n=144)$ provided the most detailed information pertaining to cause of mortality and contributory factors, thus the remainder of the results pertain to these carcasses. The CODs included Strep syndrome ( $n=63,44 \%)$; neurologic $(n=14,10 \%)$; trauma $(n=12,8 \%)$; cardiovascular ( $n=10,7 \%)$; nutritional $(n=10,7 \%)$; gastrointestinal/parasitic $(n=9,6 \%)$; could not be determined (CBD; $n=7,5 \%)$; neoplasia $(n=5,3 \%)$; non-streptococcal septicemia $(n=5$, $3 \%)$; miscellaneous $(n=5,3 \%)$ including hepatobiliary $(n=2$, $1 \%)$, oiling $(n=2,1 \%)$, and systemic histoplasmosis $(n=1$, $0.5 \%)$; HAB toxicosis $(n=2,1 \%)$; and pulmonary $(n=2,1 \%)$ (Figure 2B and Table 2). None of the animals had a COD in the categories urinary, musculoskeletal, or reproductive; however, these classifications were represented in the contributory factors.

We characterized three distinct types of Strep syndrome: infectious endocarditis $(n=44)$, septicemia $(n=13)$, and meningoencephalitis $(n=6)$. Multiple of these presentations 

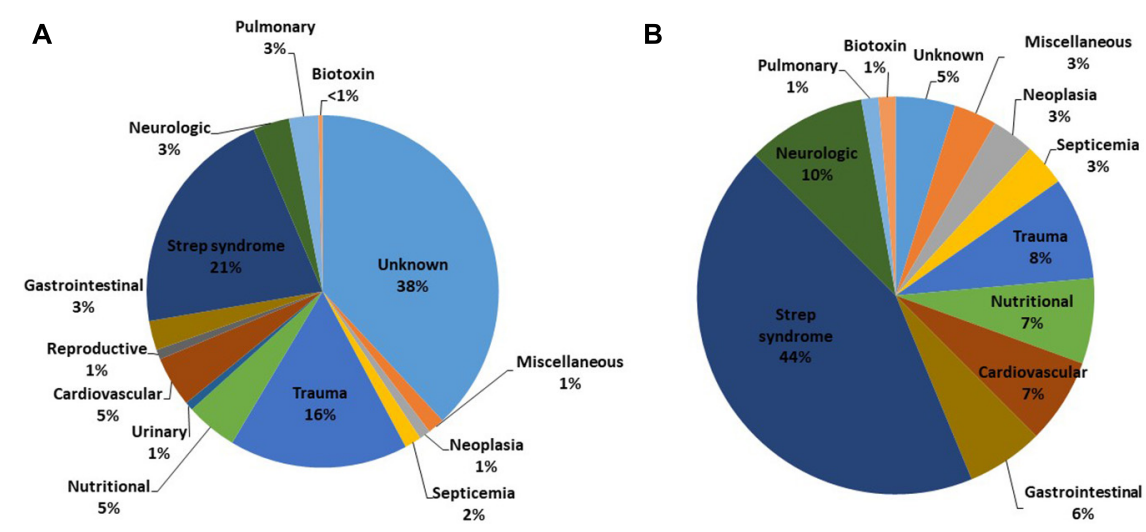

FIGURE 2 | Proximate causes of mortality for (A) all northern sea otters (Enhydra lutris kenyoni) recovered in Alaska from 2002 to 2012 ( $n=780$ ) and (B) a subset of those recovered in good condition (freshly dead, and never frozen) with complete histopathology and ancillary diagnostics ( $n=144)$. Total percentages do not add to $100 \%$ due to rounding. Causes of death classified as "miscellaneous" included oiling, hepatobiliary, and fungal diseases.

often appeared as comorbidities in one case. Infectious endocarditis was present when valves had large, tan, vegetative nodules firmly attached to and distorting them, in some cases with perforation in the valve (Figure 3 ). The aortic valve (AoV) alone was most commonly involved $(n=19)$, followed by AoV with left atrioventricular valve (LAV) combined $(n=13)$, LAV alone $(n=10)$, LAV with right atrioventricular valve (RAV, $n=1$ ), and one in which RAV, LAV, and AoV were all affected. The terminal event was often left-sided heart failure with marked distention and thinning of the left ventricle associated with severe pulmonary edema and pleural effusion. Strep syndrome was frequently complicated by extensive thromboembolic disease characterized by infarctions most frequently in the myocardium (30), followed by kidney (27), spleen (21), brain (20), at the bifurcation of the descending aorta or "saddle" (10), and sporadically in liver, adrenal gland, GI tract, pancreas, mesentery, mesenteric lymph node, skeletal muscle, and bone. These animals were frequently in thin or emaciated body condition $(n=34 / 43)$ and rarely had other preexisting lesions from which the infectious endocarditis could have originated, such as tooth root or other abscesses, discospondylitis, osteomyelitis, or other bacterial infections. The second most common presentation was septicemia due to a streptococcal organism. Many of these animals were in normal to good body condition (8/13), indicating rapid development of the process. Finally, Strep syndrome animals with meningoencephalitis as the COD had severe necrosuppurative meningoencephalitis, often with endarteritis, fibrinoid necrosis, and areas of malacia with large numbers of cocci bacteria.

Most of the streptococci isolated (Table 3) were in the SB/E complex (87\%). Of streptococci speciated at CDC, the vast majority were Streptococcus lutetiensis $(n=38$; previously Streptococcus infantarius spp. coli) with rare other members of this group including S. gallolyticus ssp gallolyticus $(n=2)$ and S. pasteurianus $(n=1)$. Strep syndrome cases peaked in 2006, then began to decline (Figure 4). In 2006, there was also a case with Streptococcus marimammalium and a few cases of mixed infection with Streptococcus lutetiensis and Streptococcus phocae $(n=4)$, and cases of Streptococcus phocae alone $(n=6)$. Although declining from 2006, SB/E cases continued to be common and primarily due to S. lutetiensis until the end of our analysis in 2012 when percentage of total cases was only $18 \%$ and numbers of cases were equal between Streptococcus lutetiensis, Streptococcus phocae, and mixed Streptococcus lutetiensis/Streptococcus phocae.

Fourteen fresh animals were coded as neurologic CODS, including five animals with suppurative encephalitis or meningoencephalitis suggestive of bacterial involvement; however, cultures were either not done or were negative for bacteria. In one of these cases, cocci bacteria were visible on histopathology, therefore it was a suspected Strep syndrome case. Four cases had non-suppurative encephalitis suggestive of protozoal or viral infection, which were all negative by serology for protozoal agents and PDV. One animal had lesions and ancillary diagnostics consistent with systemic morbillivirus infection. This was a 2009 animal from Kodiak, with lymphohistiocytic (Figure 5A) and focally suppurative encephalitis with endarteritis demonstrating fibrinoid necrosis (Figure 5B), lymphoplasmacytic sialoadenitis, interstitial pneumonia, portal hepatitis, and distinct periductal and interstitial pancreatitis. There was a single eosinophilic intracytoplasmic inclusion body within a neuron and many within biliary and pancreatic ductal epithelial cells (Figure 5C). The inclusion body in the biliary epithelium had morphology consistent with a paramyxovirus on electron microscopy (Figure 5D). Immunohistochemistry (IHC) to morbillivirus stained positive to scattered neurons (Figure 5E) and endothelial cells (Figure 5F). This animal also had mild hemorrhagic gastroenteritis, moderate lymphoplasmacytic enteritis with isolation of Vibrio alginolyticus and Vibrio parahemolyticus from blood and feces. Two animals had a lymphohistiocytic protozoal encephalitis consistent with that described in the literature (Kreuder et al., 2003). One animal had been treated at a rehabilitation facility for protozoal encephalitis and demonstrated dropping titer to T. gondii from 10,240 to 5,120. It was seronegative to $S$. neurona and N. caninum; T. gondii was isolated from the cerebrum and cerebellum. In the second 
TABLE 2 | COD and contributing factors in 144 fresh northern sea otter (Enhydra lutris kenyoni) carcasses with completed histopathology from 2002 to 2012.

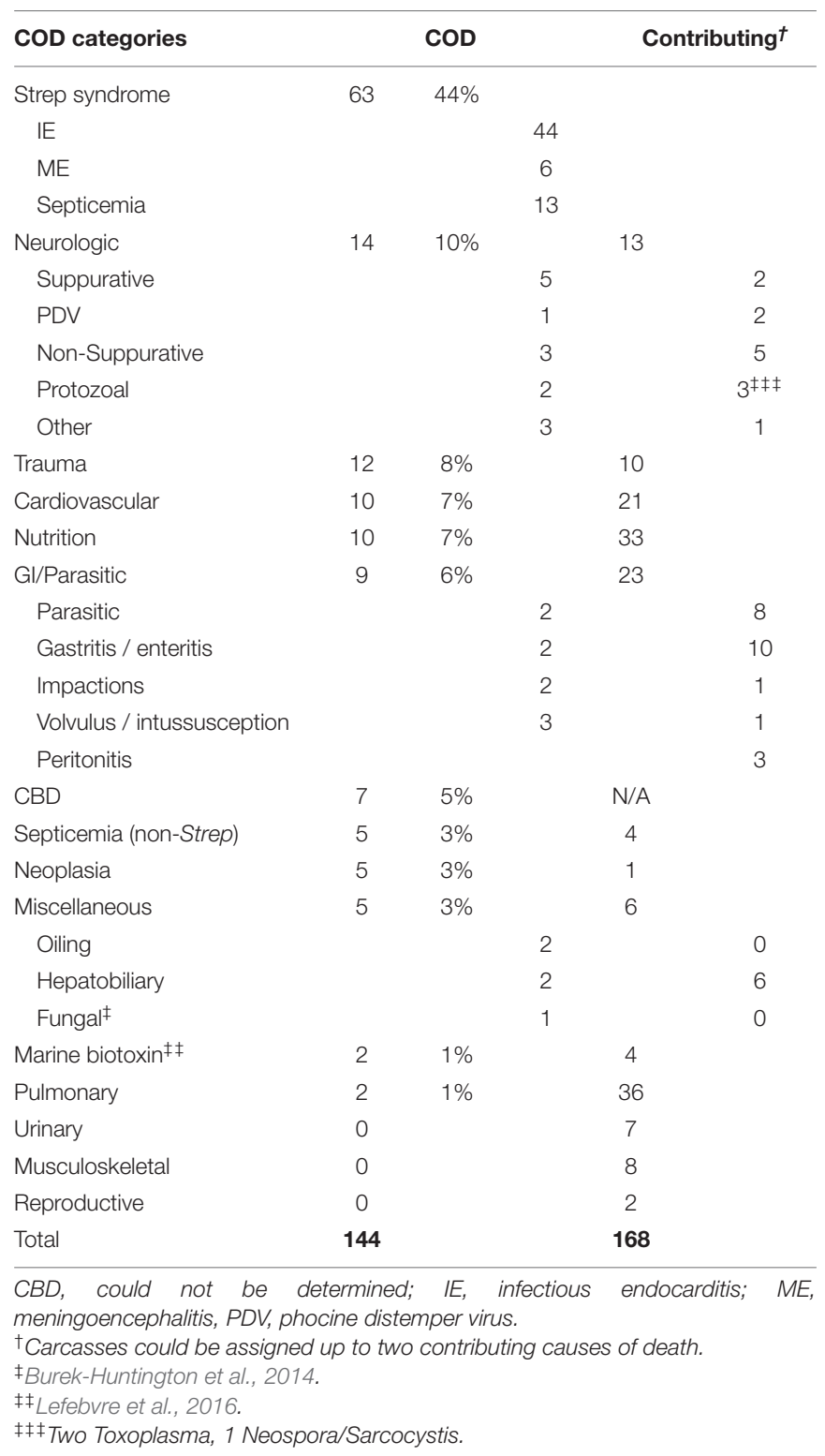

case, protozoal cysts were detected on histopathology and there was a high titer to $N$. caninum. Two other pups presented with seizure disorders. One had previous trauma to the skull with a focus of malacia in the pons, and the other had lesions consistent with congenital porencephaly with a cystic cerebrospinal fluid filled space in the left pyriform lobe and some distortion of the adjacent calvarium (Figure 6). Histologically, sections of the lesion in the pyriform lobe demonstrated a cavity in the cortex not lined by ependymal cells along with some dysplasia of the ependymal cells lining the lateral ventricle.

Trauma was another relatively common cause of death $(n=12$, $8 \%)$. Human-inflicted injuries, such as boat strike and ballistic trauma, comprised most cases $(n=10)$ but other trauma included bite wounds (probable intra- and interspecific). A geographic trend was noted for trauma with otters recovered from locations outside of the Kachemak Bay region seven times more likely to die from traumatic causes $(\mathrm{OR}=6.9,95 \% \mathrm{CI}=1.8-26.8)$. The modest sample size inhibited geographic analysis by trauma type; however, boat strikes were noted in Seward, Kodiak, Sitka, and Homer. Neither sex (two-sided chi-square test, $p=0.1637$ ) nor age (two-sided Fisher exact test, $p=0.6223$ ) were significant predictors of traumatic death. Two trauma cases had a protozoal meningoencephalitis and three had low levels of DA and/or SXT present. In the larger group, there were four presumed and 1 witnessed orca whale mortalities which were characterized by very little external trauma, blunt trauma injuries, and parallel lacerations of internal organs including liver.

Ten cases were coded as cardiovascular (7\%) for COD. Four of these cases were suspect Strep syndrome cases with IE, but streptococcal organisms were not isolated. Four animals had chronic DCM consistent with that described in southern sea otters with replacement of myocardium with fibrosis and lymphoplasmacytic inflammation and signs of right-sided heart failure. Two animals died of ruptured aortic aneurysms. Two of the animals with suspect Strep syndrome as COD had PDV as contributory factors, both with a mild non-suppurative encephalitis positive for PDV by PCR in the brain. Ten animals had cardiomyopathy as a contributory factor. These animals had proximate COD of Strep syndrome (3), HAB toxicosis (2), neoplasia, volvulus, nutrition (emaciation), septicemia, or CBD. Of these 14 animals with cardiomyopathy, one out of nine tested was positive to $T$. gondii at 80 . None of the animals with cardiomyopathy as COD were tested for HAB toxins; however, seven animals with contributory cardiomyopathy were tested for DA and SXT and included both HAB toxicosis cases and another with a low level of DA.

Nutritional diseases $(n=10)$ and gastrointestinal/parasitic $(n=9)$ CODs accounted for $7 \%$ and $6 \%$ of mortality, respectively. Recovery location outside of the Kachemak Bay region was a significant risk factor for death due to nutrition and gastrointestinal/parasitic causes $(\mathrm{OR}=5.1,95 \% \mathrm{CI}=1.3-$ 20.7; $\mathrm{OR}=7.8,95 \% \mathrm{CI}=1.5-38.9$, respectively). Animals in the nutrition category were six presumed abandoned pups, three emaciated adults, and one animal in poor body condition with severe gastrointestinal parasitism. For gastrointestinal cases/parasitic cases, there were three animals that died of intestinal volvulus with progression to peritonitis and septicemia. Two of these volvulus animals also had heart failure with associated marked ascites. Two animals had impactions of the gastrointestinal tract, one of the esophagus and the other of the colon. There were 4 single cases of different GI processes: one animal died of peritonitis related to gastric perforations due to the nematode parasite Pseudoterranova decipiens, another was an abandoned pup that had perforating gastric ulcers, another had severe Campylobacter sp. enterocolitis, and the final died due to severe mixed gastrointestinal parasitism.

There were five cases each of non-streptococcal septicemia and neoplasia (3\%). In the septicemia cases, all cases had mixed cultures from blood and tissues and some predisposing factor such as abscesses, severe tooth root abscesses, or Campylobacter enterocolitis. The five cases of neoplasia included metastatic 


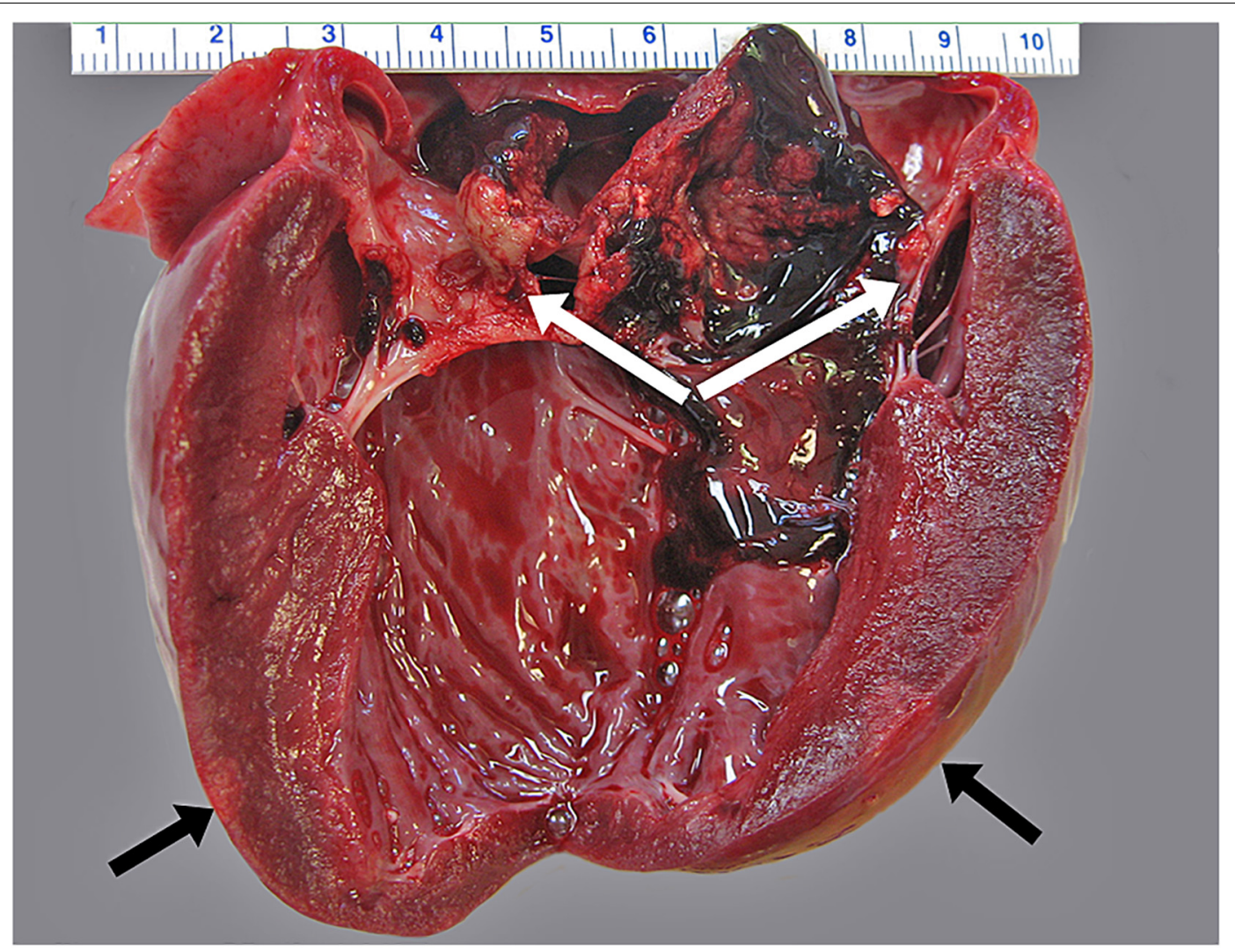

FIGURE 3 | Infectious endocarditis characterized by attachment of large, tan, and friable masses attached to the left atrioventricular heart valve (white arrows). Areas of pallor indicate myocardial infarction indicated by black arrows.

splenic hemangiosarcoma, possible malignant neuroendocrine tumor (Tuomi et al., 2006), well differentiated adrenocortical adenocarcinoma, possible pancreatic islet cell carcinoma, and metastatic malignant Sertoli cell tumor.

Miscellaneous CODs included hepatobiliary, oiling, and fungal cases. Hepatobiliary and oiling CODs were found in two animals each (Table 2). The hepatobiliary cases had severe, lobular hepatocellular necrosis of presumptive toxic etiology which had no further follow-up. The oiling cases were a consequence of the Selendang Ayu oil spill in the Aleutian Islands in 2004 (Morkill, 2005). The fungal case was a systemic histoplasmosis from Kodiak which has been previously published (Burek-Huntington et al., 2014).

Ancillary testing on the fresh cases included PDV and CDV PCR and serology, protozoology, aerobic and anaerobic bacterial cultures, DA, and SXT levels. Of the carcasses with any PDV testing $(\mathrm{n}=71), 18 \%(7 / 38)$ were confirmed positive by serology and $20 \%$ (11/55) positive by PCR, with some positive by both serology and PCR resulting in 22\% animals positive in any way (16/71). Of the 16 positive cases, the most common CODs were confirmed or suspect Strep syndrome $(\mathrm{n}=11)$, with one each of volvulus (GI), hepatic, PDV encephalitis, septicemia, and trauma. Typical pathology associated with morbilliviruses in other species, such as lymphoplasmacytic meningoencephalitis, bronchointerstitial pneumonia, and inclusion bodies, was rare. One animal died of PDV encephalitis, confirmed by EM and IHC; two others had PDV encephalitis as contributory factors. None of the animals tested by serology for CDV were positive.

Seventeen percent (14/82) of otters screened for protozoal agents had antibodies to one or more protozoal organisms including Toxoplasma gondii (11), Sarcocystis neurona (8), and Neospora caninum (7) with some animals positive for two agents.

Aerobic cultures were performed on lesions, tonsil/pharynx, and gastrointestinal tract as well as anaerobic cultures on GI samples to attempt to determine bacterial pathogens involved with pathology and also likely origin for systemic Streptococcal infections. Streptococcal organisms involved in Strep syndrome were discussed above. Thirty-one percent of animals with GI contents cultured $(n=122)$ demonstrated SB/E species (S. lutetiensis, S. bovis non-specified, S. gallolyticus ssp gallolyticus, and S. gallolyticus ssp pasteurianus) while $7 \%$ demonstrated gastrointestinal $S$. phocae, the second most common cause of Strep syndrome. Only 9\% $(n=67)$ of tonsils yielded $\mathrm{SB} / \mathrm{E}$ organisms, while $25 \%$ yielded S. phocae (Table 3 ). Fecal pathogens, including hemorrhagic E. coli and E. coli 0157:H7, Campylobacter spp., and Salmonella enterica, were rarely detected. Vibrio sp., primarily $V$. parahemolyticus, were detected in $13 \%$ of animals tested. 
Marine biotoxin concentrations were detected in 29\% (21/72) of the otters screened: DA was detected in 26\% (19/72) and saxitoxin in $20 \%(11 / 56)$ with some animals positive for both toxins. Levels for DA ranged from 0.4 to $65 \mathrm{ng} / \mathrm{g}$ and saxitoxin 4.26-541 ng/g (Table 3) with average levels of 4 and $13 \mathrm{ng} / \mathrm{g}$, respectively. There were two cases in which $\mathrm{COD}$ was attributed to HAB toxins; one a pregnant female in 2004 and the other an adult male in 2008 with lesions in the brain suggestive of DA toxicosis, including segmental superficial neuronal cytoplasmic swelling and vacuolation, including hippocampus and rhinencephalon. The term fetus of the female had high levels of saxitoxin (541.076 ng/g) in pleural fluid. The other 19 toxin positive animals had COD of Strep syndrome $(n=5)$, trauma $(n=4)$, nutritional $(n=4)$, neurologic $(n=3)$, and one each of $\mathrm{GI} /$ parasitism, septicemia and hepatobiliary.

\section{DISCUSSION}

Our results revealed that the causes of mortality for stranded sea otters in Alaska for this time period differ greatly from those previously reported other sea otter populations. Prior to this study, the Strep syndrome-like pattern of mortality had not been reported for sea otters or other marine mammals. We also report pathology due to a PDV-like virus in a small number of animals, a pattern of mortality very different from that described in northern sea otters on the coast of Oregon and Washington and threatened southern sea otters in California. Our data set from 2002 to 2012 reflects the management team at the time, which initiated and continued a dedicated necropsy program and was consistently present during this time period. A subsequent effort to continue mortality surveillance from 2013 to present has been conducted by the current management team at USFWS and the National Wildlife Health Center.

\section{Demographics}

Although sea otters were recovered throughout their range in Alaska, most of the carcasses were from the SC stock, which overlaps with the largest human population base in Alaska. Within this stock, a large proportion of carcasses were from Kachemak Bay $(\mathrm{KB})$, which has a robust marine mammal stranding network, a strong conservation ethic, and accessible beaches, unlike much of the more remote and less densely populated shoreline in Alaska. Also, the geology and oceanography of KB may lend itself to increased carcass recovery. The Homer Spit, an area highly trafficked by people, dissects KB into inner and outer zones. Due to the movement of longshore currents and surface gyres in KB (Burbank, 1977), the spit serves as a catchment area for marine debris. Distribution surveys have shown the spit and adjoining bays are key habitat for sea otters (Gill et al., 2009), and about 6,000 otters are estimated to inhabit KB (Garlich-Miller et al., 2018), which is twice the size of the entire population of the endangered southern sea otter in California (Hatfield et al., 2019).

Carcass recovery peaked between 2006 and 2010 and most carcasses were recovered during spring and summer from April to August. The reason for the increase in cases 2006 to 2010 is unknown but is possibly due in part to the development of the Alaska marine mammal stranding network (AMMSN) beginning 2003 and an increased effort in outreach to the public to report all marine mammal, and in particular sea otter, strandings, which had garnered strong community support by 2005. In 2006 a UME was declared for northern sea otters in Alaska and with this declaration came media coverage, public service announcements, and community concern leading to more stranded sea otters getting reported. Why there was a drop in recovered otter carcasses after 2010 is unknown as outreach and support for the project were still strong. While the AMMSN has gone from strength to strength since its inception, there has

TABLE 3 | Ancillary testing data for fresh carcasses with completed histopathology $(n=144)$.

\begin{tabular}{|c|c|c|c|c|}
\hline Agent/Organism & \# POS & \# Tested & $\%$ POS & Comments \\
\hline \multicolumn{5}{|l|}{ Bacterial agents } \\
\hline SS confirmed cases & 63 & 144 & $44 \%$ & \\
\hline S. lutetiensis & 38 & 63 & $60 \%$ & \\
\hline SB/E non-specified & 9 & 63 & $14 \%$ & \\
\hline S. phocae & 6 & 63 & $10 \%$ & \\
\hline S. lutetiensis / S. Phocae & 5 & 63 & $8 \%$ & \\
\hline $\begin{array}{l}\text { S. gallolyticus ssp } \\
\text { gallolyticus }\end{array}$ & 2 & 63 & $3 \%$ & \\
\hline $\begin{array}{l}\text { S. gallolyticus ssp } \\
\text { pasteurianus }\end{array}$ & 1 & 63 & $2 \%$ & \\
\hline S. marimammaliam & 1 & 63 & $2 \%$ & \\
\hline S. Viridans & 1 & 63 & $2 \%$ & \\
\hline \multicolumn{5}{|l|}{$\begin{array}{l}\text { Bacterial fecal } \\
\text { pathogens }\end{array}$} \\
\hline$S B / E$ & 38 & 122 & $31 \%$ & \\
\hline S. phocae & 9 & 122 & $7 \%$ & \\
\hline Vibrio sp. & 16 & 122 & $13 \%$ & $\begin{array}{l}\text { V. alginolyticus (5), } \\
\text { V. parahemolyticus } \\
\text { (12), V. cholerae (1) }\end{array}$ \\
\hline Campylobacter sp. & 11 & 122 & $9 \%$ & \\
\hline Salmonella sp. & 4 & 122 & $3 \%$ & \\
\hline \multicolumn{5}{|l|}{ Tonsil / Oropharyngeal } \\
\hline$S B / E$ & 6 & 67 & $9 \%$ & \\
\hline S. phocae & 17 & 67 & $25 \%$ & \\
\hline \multicolumn{5}{|l|}{$\begin{array}{l}\text { Phocine distemper virus } \\
\text { (PDV) }\end{array}$} \\
\hline PDV serology ${ }^{a}$ & 7 & 38 & $18 \%$ & $1: 40-1: 1280$ \\
\hline CDV serology & 0 & 27 & $0 \%$ & \\
\hline PCR & 11 & 55 & $20 \%$ & \\
\hline \multicolumn{5}{|l|}{ Protozoal serology ${ }^{b}$} \\
\hline Toxoplasma gondii & 11 & 82 & $13 \%$ & $1: 40-1: 40,960$ \\
\hline Sarcocystis neurona & 8 & 82 & $10 \%$ & $1: 40-1: 1280$ \\
\hline Neospora caninum & 7 & 82 & $9 \%$ & $1: 40-1: 160$ \\
\hline \multicolumn{5}{|l|}{ Marine biotoxins } \\
\hline Domoic acid & 19 & 72 & $26 \%$ & $0.12-65 \mathrm{ng} / \mathrm{g}$ \\
\hline Saxitoxin & 11 & 56 & $20 \%$ & $4.26-541 \mathrm{ng} / \mathrm{g}$ \\
\hline
\end{tabular}

SS, strep syndrome.

a Serum neutralization test titers $>32$ were considered positive.

${ }^{b}$ Titers > 320 on the serological immunofluorescent antibody test (IFAT) were considered supportive of infection by protozoal organisms. 
Numbers and percentages of Strep syndrome cases by species over time

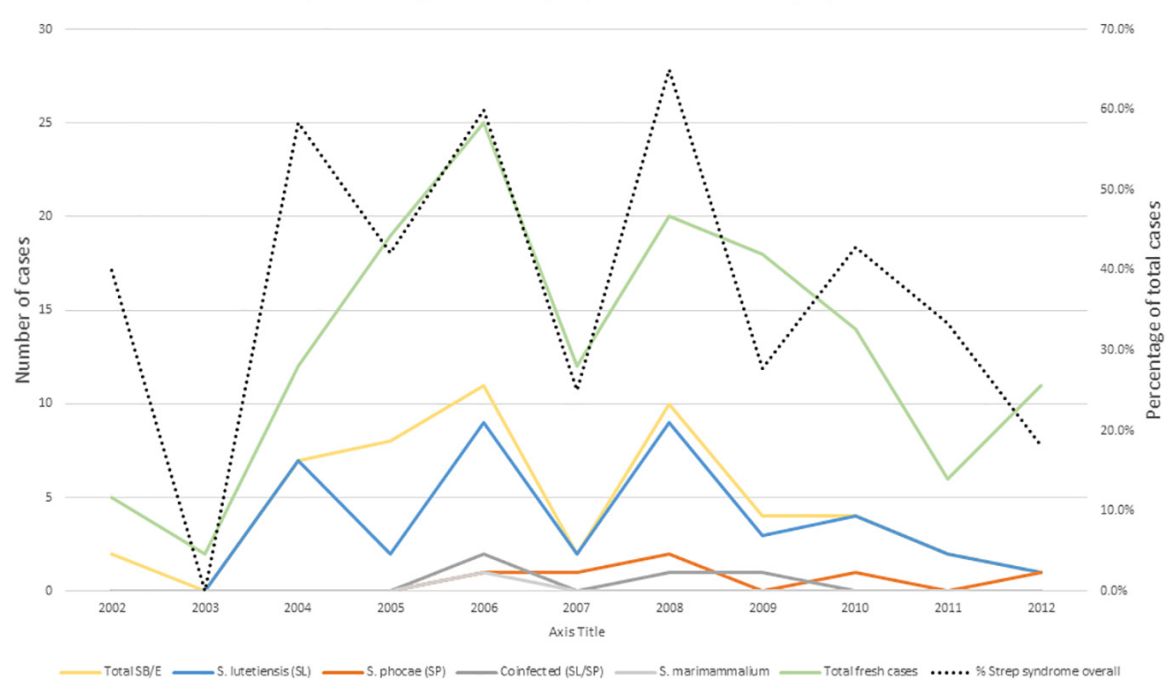

FIGURE $\mathbf{4}$ | Streptococci responsible for the Strep syndrome cases by year in fresh northern sea otters. Total Streptococcus bovis/equinus include S. Iutetiensis (SL), S. gallolyticus ssp gallolyticus, S. gallolyticus ssp pasteurianus, and Streptococcus bovis/equinus non-specified. Doted black line indicates percent of Strep syndrome cases over total analyzed cases.

been a de-emphasis on sea otter carcass recovery since 2014 and any future analysis on sea otter mortality trends must consider this. The seasonal pattern described in this analysis may be due to inclement weather keeping the public off the beaches during the winter months, as well as carcasses being obscured by snow and ice, rather than a true reflection of mortality rates. In a study of the SE AK stock where 31 sea otters were tracked for 3 years, most of the mortality also occurred in the summer months and was primarily due to hunting by Alaska Natives (Hoyt et al., 2014). This finding is contrary to what has been previously described with maximum mortality among northern sea otters in the western Aleutians during the winter and early spring, associated with a period of environmental stress (Kenyon, 1969; Bodkin et al., 2000).

On average, twice as many male carcasses were recovered annually compared with females and our analysis showed that location of recovery was not predictive of sex. This male bias could perhaps be explained by the behavioral ecology of sea otters. Sea otters segregate in areas by sex with distinct male, mom/pup, and resting areas (Garshelis et al., 1984; Riedman and Estes, 1990; Doroff and Badajos, 2010). Earlier studies on the species have shown that it is not unusual for mortality in sea otter populations to be male-biased (Kenyon, 1969; DeGange and Vacca, 1989). Various hypotheses include sexual segregation and the high densities of males associated with this, as well as male-male competition (Bodkin et al., 2000).

More adult carcasses were recovered compared with all other age classes throughout the study period, which is similar to the analyses from California (Kreuder et al., 2003). Subadults of both sexes were much more likely to be underweight than other ages. This finding may be due to failure to thrive, social marginalization, and competition for foraging territories common for this age class, possibly in combination with other differential health stressors for this group, including the proportionately high occurrence of Strep syndrome with IE.

\section{Strep Syndrome}

Strep syndrome was by far the most common COD, and these cases were primarily recovered from KB. Subadults were more commonly affected by this disease, the reason for which is unknown. Our analysis did not show a correlation between Strep syndrome cases and sex, suggesting that males and females were equally susceptible to the condition or its predisposing factors. The most common presentation of Strep syndrome was IE, which appears to be a relatively new phenomenon. Out of 282 sea otter carcasses necropsied after the 1989 Exxon Valdez oil spill, only one was reported with IE, due to an unknown organism (Lipscomb et al., 2013). Early cases of IE were noted in an animal from Kodiak in 1989 (DeGange and Vacca, 1989) and an animal from Prince William Sound that died at Sea World San Diego shortly after arrival in 1990 and bacterial agents were not determined (Joseph et al., 1990).

In most of the Strep syndrome cases, there were no correlations with preexisting lesions typically associated with IE in humans and domestic animals, such as tooth root abscess, discospondylitis, osteomyelitis, or other chronic bacterial infections. In our sea otter cases, other lesions observed on histopathology in concert with IE included mild to moderate eosinophilic enteritis, likely as a result of endoparasitism. The chronically inflamed gastrointestinal tract likely provides a portal of entry for these bacterial pathogens, as Strep syndrome cases also more frequently had isolates of streptococcal organisms within the mesenteric lymph nodes and GI tract compared with animals that died of other causes. 


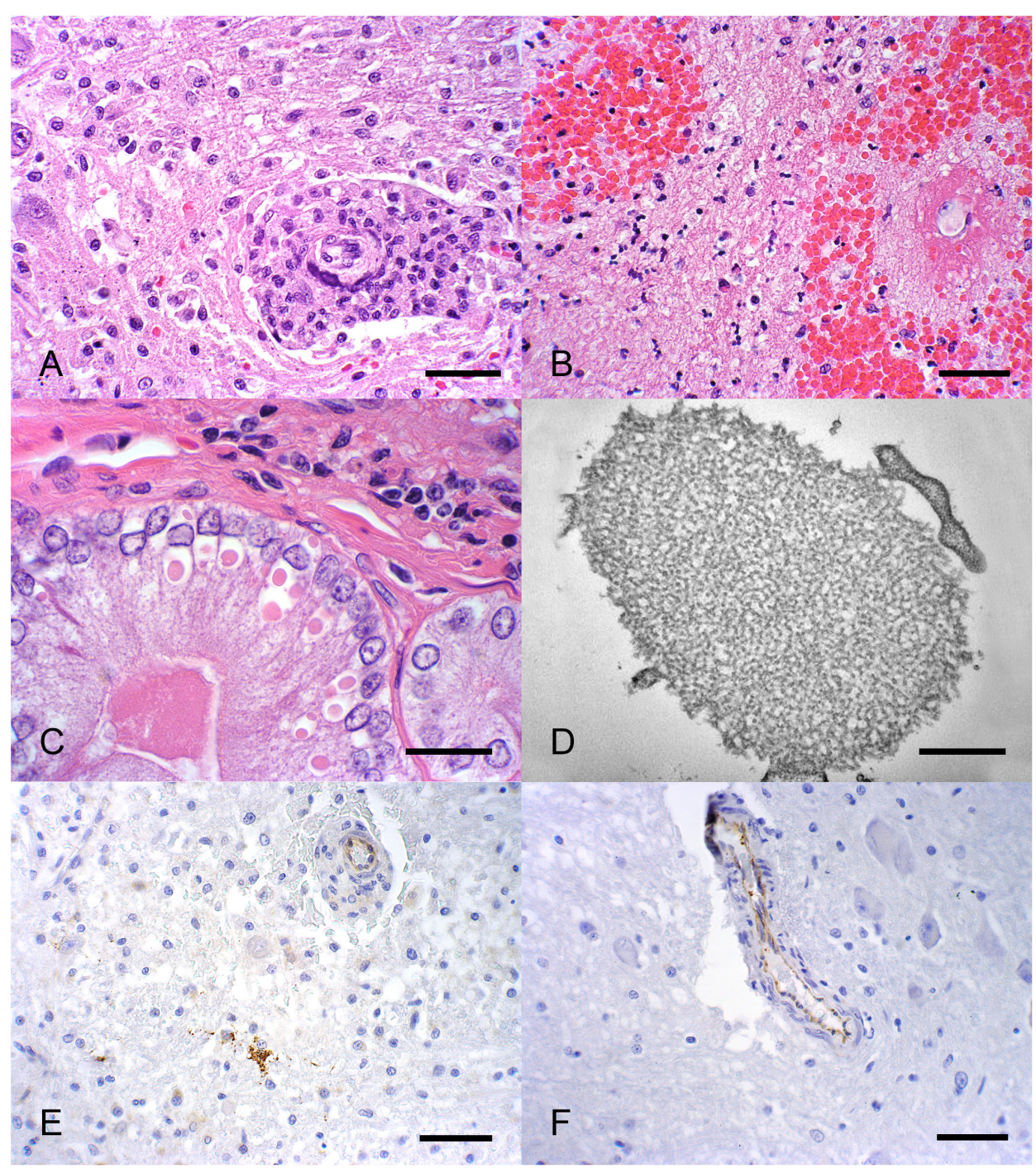

FIGURE 5 | (A) Encephalitis characterized by perivascular lymphohistiocytic in a phocine distemper virus-positive sea otter (magnification $400 \times$; scale bar = $40 \mu \mathrm{m}$ ). (B) Focal, perivascular, suppurative encephalitis with endarteritis and fibrinoid necrosis (magnification 400x; scale bar $=40 \mu \mathrm{m}$ ). (C) Eosinophilic intracytoplasmic inclusion bodies present in biliary and pancreatic epithelial cells (magnification 400x; scale bar $=40 \mu \mathrm{m}$ ). (D) Electron microscopy of pancreatic cells with viral structures consistent with a paramyxovirus infection (magnification 46460x; scale bar $=500 \mathrm{~nm}$ ). (E) Immunohistochemistry for morbillivirus highlighted rare neurons (F) and endothelial cells as positive (magnification $400 \times$; scale bar $=40 \mu \mathrm{m}$ ).
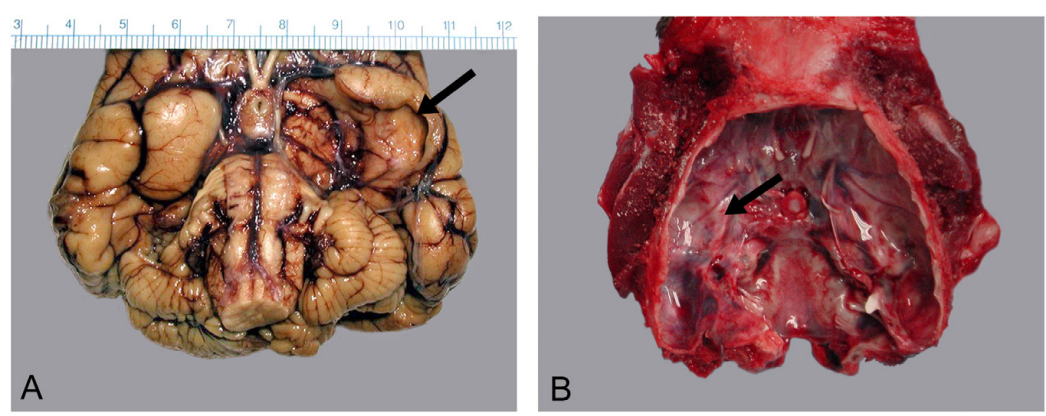

FIGURE 6 | Congenital porencephaly of the piriform lobe in a 9-month-old sea otter pup. (A) Ventral surface of the formalin fixed brain with the arrow indicating the collapsed cyst in the brain and (B) the deformation of the calvarium. 
Most Strep syndrome cases were infected with members of the SB/E group, primarily S. lutetiensis (Poyart et al., 2002). The pathogenesis and origin of the $S$. lutetiensis bacteria are poorly understood. Animals that died of other etiologies generally did not have SB/E or other streptococci isolated from the gastrointestinal or oropharyngeal swabs. Attempts to isolate this bacteria from environmental sources, such as bivalves, have been variably successful, but the pattern of presence in the GI suggests that an environmental/food source is the probable route of infection (Counihan-Edgar et al., 2012). S. lutetiensis has multiple pathogenic properties that may be important to host colonization, invasion, and disease, including the adherence to ground substance, ability to survive phagocytosis by macrophages, and adherence and invasion of endothelial and epithelial cells (Counihan et al., 2015). It is unknown whether there could have been an increase in virulence to explain the increase in cases; however, this seems unlikely considering the drop in cases after 2010. Infectious endocarditis associated with S. bovis (not characterized to species) has been described in domestic mink (Mustela vison) in outbreak patterns (Pedersen et al., 2003). In these cases, a preexisting condition also could not be determined, similar to northern sea otters. Sporadic cases of septicemia and infectious endocarditis due to S. lutetiensis have been seen in the southern sea otter population in California but are rare, occurring in only 4 of 281 carcasses collected and necropsied along the central California coast between 2004 and 2008 (Counihan-Edgar et al., 2012). Members of the SB/E group are also important pathogens in humans. S. lutetiensis has been described in a case of bacteremia in a person (Almuzara et al., 2013); S. gallolyticus ssp gallolyticus is an emerging pathogen in humans correlated with IE and bacteremias along with colonic polyps and adenocarcinomas (Herrero et al., 2002; Abdulamir et al., 2011). These correlations of different species of SB/E with various diseases indicates that characterization of streptococcal species is of importance in understanding the epidemiology of these diseases and organisms.

In other host species, several organisms such as Erysipelothrix rhusiopathiae in swine, Bartonella spp. in dogs (Lepidi et al., 2000; Pesavento et al., 2005), and Coxiella spp. are associated with IE and thought to be primary pathogens (Duncan et al., 2015). Bartonella spp. and Coxiella sp. can be difficult to culture, therefore studies using the samples reported here were performed in order to determine whether initial damage to endothelium by these organisms correlated to Strep syndrome. In these previously published studies, Bartonella spp. were detected by PCR in northern sea otters at a higher rate in AK than in California; however, a direct correlation to Strep syndrome was not found (Carrasco et al., 2014a; Carrasco et al., 2014b). Coxiella burnetii was not detected in heart valve lesions by PCR (Duncan et al., 2015). Immunosuppression could be an explanation for the frequency of Strep syndrome in northern sea otters, and possible causes include malnutrition, viral infections such as by morbilliviruses or retroviruses, organohalogen contaminants, and decreased population genetic variability. Morbillivirus consistent with PDV was detected in these northern sea otters, has not reported in southern sea otters, and is a possible factor in the high rate of Strep syndrome. Levels of organohalogens and perfluorinated chemicals have been detected in northern sea otters but at lower levels than in southern sea otters, and levels are decreasing over time (Hart et al., 2009; Harley et al., 2019).

\section{Phocine Distemper Virus (PDV)}

It is possible that susceptibility to Strep syndrome is associated with immunosuppression or pathology due to previous phocine distemper virus infection (Goldstein et al., 2009; Goldstein et al., 2011). Almost a quarter of fresh cases were confirmed positive for PDV by PCR and/or serology. Partial sequence analysis of the $\mathrm{P}$ gene showed identity with PDV from the Europe 2002 variant and close alignment with PDV from Europe 1988. These results were initially surprising considering there have not been PDV mortality events on the Pacific coast as seen in harbor and gray seals in northwestern Europe and Atlantic coast of the United States. PDV is endemic in gray and harp seals, and they are likely reservoir species for the virus in the Atlantic. With PDV detected first in northern sea otters with closest sequence data to the 2002 European variant associated with low ice years in the Arctic, it is possible there has been transmission of this virus into the Pacific via Arctic waters due to reduced sea ice cover related to climate change (Goldstein et al., 2009). Testing of seals, sea lions, and sea otters sampled in the North Pacific Ocean from 2001 to 2016 investigated the timing of PDV introduction, risk factors associated with PDV emergence, and patterns of transmission following introduction with a peak in 2003 and another in 2009 (VanWormer et al., 2019). In our case series, there were cases of non-suppurative encephalitis, positive by PCR and IHC for PDV with rare inclusion bodies in the brain, liver, and pancreas with electron microscopy consistent with a paramyxovirus. Typical bronchointerstitial pneumonia with inclusion bodies and syncytial cells in the lung and urothelium were not seen in any of the cases. Interestingly, positive immune staining of endothelial cells associated with fibrinoid necrosis demonstrated in one case is reminiscent of pathology seen with other morbillivirus including Hendra and Nipah viruses (Hooper et al., 2001). It is possible that pathology of this morbillivirus manifests differently in this species, or perhaps this represents a different variant of the virus with slightly different pathology and pathogenesis. It is possible that one contribution of morbillivirus infection in some of these northern sea otters is damage to endothelial cells with resultant pathology in the heart and brain and/or immunosuppression, which could partially explain the high frequency of Strep syndrome. Isolation and characterization including full sequencing of this virus may help to answer these questions.

\section{Trauma}

Trauma was another common COD and was primarily due to human interaction. Rates of death by trauma did not differ by sex. Otters recovered from locations outside of $\mathrm{KB}$ were more than nearly seven times as likely to die from trauma. This difference is likely related to the carcass quality of many of the non-KB cases, as some CODs, including trauma, are more easily diagnosed in more autolyzed carcasses than other causes. Neurologic disease would be highly under-represented in the lower quality carcasses because the brain would not be examined 
histologically. In California, great white shark bites were listed as the second highest cause of death (Kreuder et al., 2003), and rates of attacks increased between 2003 and 2013, in which year it was the highest cause of death (Tinker et al., 2016). We did not report any mortalities due to shark attack, which is likely because the range of great white sharks does not often extend into Alaska. Conversely, we reported mortalities consistent with orca attacks, which have not been reported in California.

\section{Comparison to Mortality Patterns in Washington/Oregon and California}

The patterns of mortality detected in this study have some similarities but mostly differ from other studies in sea otter populations. The bias toward adults in our analysis was similarly reported in southern sea otters (Kreuder et al., 2003) and northern sea otters in Russia during a die-off (Bodkin et al., 2000) and in Oregon and Washington (White et al., 2018). Kreuder et al. (2003) concluded that the high percent of prime-aged adult mortality, along with a high prevalence of disease in this age class, was not consistent with a healthy population destined for recovery. Similar to other studies, our top COD was infectious disease, with Strep syndrome most common in our study, while protozoal encephalitis and acanthocephalan infection were most common in southern sea otters in California (Kreuder et al., 2003), and protozoal encephalitis due primarily to Sarcocystis neurona was most common in northern sea otters in Oregon and Washington (White et al., 2018). Prevalence of confirmed or suspect protozoal encephalitis was very low in our population.

Although not frequently a proximate COD of northern sea otters, the presence of protozoal organisms may have played a part in contributing to mortality and may be demonstrating an increasing presence in this region. A few earlier studies of the species have evaluated exposure of free-ranging animals in Alaska to protozoal organisms, in particular Toxoplasma gondii. Two earlier studies in live-captured northern sea otters had evidence of no exposure to T. gondii (Hanni et al., 2003; Hoyt et al., 2014), and one found low exposure rates of 3\% (Goldstein et al., 2011). Our analysis, although conducted on stranded otters and thus more likely to be diseased or debilitated, demonstrated an overall prevalence of $T$. gondii exposure of 13\%. Toxoplasma gondii is a globally ubiquitous protozoan parasite capable of infecting all warm-blooded animals, including humans, and is a significant cause mortality in southern sea otters in California (Kreuder et al., 2003; Miller et al., 2004; Jessup et al., 2007) and northern sea otters in Washington state (Verma et al., 2018). The definitive host for Toxoplasma gondii is both domestic and wild felids, and in California it has been suggested that land-to-sea pathogen transport has occurred as a result of expansion of domestic cat populations as well as decreased natural filtration of watershed runoff through coastal estuaries, thereby increasing sea otter exposure to T. gondii oocysts (VanWormer et al., 2016). Lower human density may partly explain why Alaska has such a lower rate of transmission, as fewer people correlates with a smaller domestic cat population.

Another major COD in California which had very low rates in Alaska was DCM, characterized by replacement of myocardium with chronic lymphoplasmacytic myocarditis and fibrosis progressing into right-sided heart failure. In California, myocarditis is correlated with exposure to both Sarcocystis neurona and domoic acid in southern sea otters and DCM correlated with exposure to domoic acid alone (Kreuder et al., 2003; Kreuder et al., 2005; Zabka et al., 2009). In our study, DCM was the COD for four animals and a secondary factor in 10 animals. This low rate in northern sea otters in Alaska supports the idea that Sarcocystis neurona and domoic acid may be involved in the pathogenesis of DCM due to our relatively low prevalence of this disease agent and low levels of DA.

Low levels of the biotoxins DA and STX, responsible for amnesic and paralytic shellfish poisoning (PSP), respectively, were detected in almost a third of sea otters tested in this study with DA most commonly detected. DA is a naturally occurring marine neurotoxin produced during seasonal algal blooms, typically associated with warmer water temperatures than has historically been seen in Alaska. The presence of DA was first documented in Alaska in the early 1990s in shellfish from SE, AK, and KB (RaLonde and Wright, 2011) and in a sea otter necropsied for USFWS in 2000. The fact that DA was detected at low levels in $26 \%$ of otters tested from Alaska, but was only implicated in $1 \%$ of mortalities, suggests that either mortality due to DA may be underestimated or that most exposures were at subclinical levels in this region.

Paralytic shellfish poisoning is a known human health hazard in Alaska with shellfish harvest being an important commercial as well as subsistence resource in Indigenous communities (Lewitus et al., 2012) and appears to be increasing with climate factors (Tobin et al., 2019). Saxitoxin was found in $22 \%$ of the otters tested and acute toxicosis may have contributed to at least two boat strike fatalities in November 2009 in the Kodiak boat harbor. Live capture of otters in SE AK in May 2011 found that 95\% of the animals were positive for SXT (Hoyt et al., 2014) which suggests otters may not be able to avoid PSPs as easily as previously thought (Kvitek and Bretz, 2004) and likely have chronic low-level exposure. DA was detected in 13 species and SXT in 10 species of marine mammals tested from southeast Alaska to the Arctic from 2004 to 2013 (Lefebvre et al., 2016), including subsistence-harvested and stranded animals, evidence that biotoxins are now widespread in the Subarctic and Arctic but not necessarily at high enough levels to cause toxicosis. A review of changes in marine mammal health in North America since 1972 found that toxicoses from harmful algal blooms appear to be increasing (Simeone et al., 2015). We suggest that, when possible, sea otters should be tested for biotoxins and the results used to alert shellfish managers where there may be hotspots and risks to human health.

Our results indicate a possible increase in exposure and/or susceptibility of northern sea otters to infectious pathogens and highlight possibilities for changing pathogen availability, distribution, and virulence. Increasing causes of death may well be related to climatic variability facilitating exposure to pathogens and toxins. A review of changes in marine mammal health in North America since 1972 found that viral epidemics are most common along the Atlantic U.S. coastline, while bacterial epidemics, primarily leptospirosis, are most common along the Pacific coast of California (Simeone et al., 2015). The presence of 
recurring infections and/or unusual mortality events can hamper recovery of threatened and endangered populations or lead to population declines in growing or stable stocks. Understanding causes of mortality is vital for understanding the cumulative impacts of stressors, such as development in the nearshore environment, on northern sea otter health. Due to the potential for some diseases and biotoxins found in northern sea otters to also affect human health, continued monitoring, accurate detection, and analysis of fresh northern sea otter strandings are needed. As climate change continues to affect the Arctic and subarctic, and ocean temperatures increase, novel health effects on marine mammals in this region are likely to continue to occur (Burek et al., 2008) and it is possible Strep syndrome may be one of these changes. An enhanced understanding of the high prevalence of Strep syndrome, particularly among subadult otters that have yet to reproduce, is needed to better assess and monitor the potential for long-term, population-level effects from this disease process.

\section{DATA AVAILABILITY STATEMENT}

The original contributions presented in the study are included in the article/supplementary material, further inquiries can be directed to the corresponding author.

\section{ETHICS STATEMENT}

Ethical review and approval was not required for the animal study because the study was performed using dead northern sea otters submitted for necropsy to the United States Fish and Wildlife Service (USFWS) or the Alaska SeaLife Center (ASLC) and necropsies were performed by contract under their permits.

\section{AUTHOR CONTRIBUTIONS}

$\mathrm{KB}$ directed the case investigations, conducted gross and histopathologic analysis, completed a literature review, and wrote the manuscript. VG managed the stranding and necropsy program at USFWS, provided funding, and conceptualized and edited the manuscript. $\mathrm{AB}$ conducted the statistical analysis and assisted with manuscript preparation and review. TG performed the virological analysis and provided input during the manuscript editing. PT assisted with gross necropsies and with manuscript review. BB performed the microbiology analysis and helped with manuscript editing. KW assisted with gross necropsies,

\section{REFERENCES}

Abdulamir, A. S., Hafidh, R. R., and Bakar, F. A. (2011). The association of Streptococcus bovis/gallolyticus with colorectal tumors: the nature and the underlying mechanisms of its etiological role. J. Exp. Clin. Cancer Res. 30:11.

Almuzara, M., Bonofiglio, L., Cittadini, R., Vera Ocampo, C., Montilla, A., Del Castillo, M., et al. (2013). First case of Streptococcus lutetiensis bacteremia involving a clindamycin-resistant isolate carrying the $\operatorname{lnuB}$ gene. J. Clin. Microbiol. 51, 4259-4261. doi: 10.1128/JCM.01774-13 managed data and sample handling, and assisted with manuscript editing. JM provided oversight for the epidemiological analysis, interpreted results, and edited the manuscript. All authors contributed to the article and approved the submitted version.

\section{FUNDING}

This work was funded by the Marine Mammals Management office of the USFWS and ALSC.

\section{ACKNOWLEDGMENTS}

We appreciate the many members of the volunteer Alaska marine mammal stranding network, as well as interns and biologists that assisted us on the beaches and in the laboratory. Special thanks go to all the staff at the Alaska SeaLife Center that fielded calls, helped with logistics, and lent a hand on necropsies. The people involved are too numerous to mention by name but that does not lessen the gratitude we have to each and every one of them. This study would not have been possible without their dedication. In particular, we thank Angela Doroff, John Haddix, Dana Jenski, Doug Burn, Karen Corbell, Rachael Rooney, Deborah Boege Tobin, Leslie Slater, Arthur Kettle, Marc Webber, Michael Opheim, Mike Miller, Tonya Lee, Kate Wynne, and Tim Lebling for their long-term and enthusiastic support. We are indebted to veterinarians Carrie Goertz, Joanne Hill, and Marc Kramer for their help with multiple necropsies and to veterinary pathologists Jennifer Chilton, David Rotstein, and Melissa Miller for their help with histology and interpretation. The WARRN-west laboratory with Dr. Kathi Lefebvre and Maryjean Willis provided DA and SXT analysis, and Dr. Patricia Conrad and UC Davis Protozoal laboratory provided the analyses for Toxoplasma, Sarcocystis and Neospora. Thanks to Christie Buie of NorthWest ZooPath for assistance with photomicrograph preparation. Finally, a big thank you to Jim Bodkin for encouraging us to begin the study. Carcasses and samples were collected under MMPA permit No. MA041309-5 issued to VG in the U.S. Fish and Wildlife's Marine Mammals Management office. We appreciate seed money provided to VG from the Oiled Wildlife Care Network and the Minnesota Zoo Conservation Fund to begin the northern sea otter health and disease program. Most funding for this study was provided by the U.S. Fish and Wildlife Service. The findings and conclusions in this article are those of the authors(s) and do not necessarily represent the views of the U.S. Fish and Wildlife Service. 
Bogomolni, A. L., Pugliares, K. R., Sharp, S. M., Patchett, K., Harry, C. T., LaRocque, J. M., et al. (2010). Mortality trends of stranded marine mammals on Cape Cod and southeastern Massachusetts, USA, 2000-2006. Dis. Aquat. Organ. 88, 143-155. doi: 10.3354/dao02146

Bossart, G. D. (2011). Marine mammals as sentinel species for oceans and human health. Vet. Pathol. 48, 676-690. doi: 10.1177/0300985810388525

Burbank, D. C. (1977). "Circulation studies in Kachemak Bay and lower Cook Inlet," in Environmental Studies of Kachemak Bay and Lower Cook Inlet, eds L. L. Trasky, L. B. Flagg, and D. C. Burbank, (Anchorage, AK: Alaska Department of Fish and Game), 1-207.

Burek, K. A., Gulland, F. M., and O'Hara, T. M. (2008). Effects of climate change on Arctic marine mammal health. Ecol. Appl. 18(Suppl. 2), S126-S134. doi: 10.1007/978-3-642-24203-8_1

Burek-Huntington, K. A., Gill, V., and Bradway, D. S. (2014). Locally acquired disseminated histoplasmosis in a northern sea otter (Enhydra lutris kenyoni) in Alaska, USA. J. Wildl. Dis. 50, 389-392. doi: 10.7589/2013-11-288

Poyart, C., Quesne, G., and Trieu-Cuot, P. (2002). Taxonomic dissection of the Streptococcus bovis group by analysis of manganese-dependent superoxide dismutase gene (sodA) sequences: reclassification of' Streptococcus infantarius subsp. coli as Streptococcus lutetiensis sp. nov. and of Streptococcus bovis biotype 11.2 as Streptococcus pasteurianus sp. nov. Int. J. Syst. Evol. Micr. 52, 1247-1255. doi: 10.1099/ijs.0.02044-0

Carrasco, S. E., Chomel, B. B., Gill, V. A., Doroff, A. M., Miller, M. A., BurekHuntington, K. A., et al. (2014a). Bartonella spp. Exposure in northern and southern sea otters in Alaska and California. Vector-Borne Zoonotic Dis. 14, 831-837. doi: 10.1089/vbz.2014.1612

Carrasco, S. E., Chomel, B. B., Gill, V. A., Kasten, R. W., Maggi, R. G., Breitschwerdt, E. B., et al. (2014b). Novel Bartonella infection in northern and southern sea otters (Enhydra lutris kenyoni and Enhydra lutris nereis). Vet. Microbiol. 170, 325-334. doi: 10.1016/j.vetmic.2014.02.021

Chinn, S. M., Miller, M. A., Tinker, M. T., Staedler, M. M., Batac, F. I., Dodd, E. M., et al. (2016). The high cost of motherhood: end-lactation syndrome in southern sea otters (Enhydra lutris nereis) on the Central California Coast, USA. J. Wildl. Dis. 52, 307-318. doi: 10.7589/2015-06-158

Counihan, K. L., Gill, V. A., Miller, M. A., Burek-Huntington, K. A., Lefebvre, R. B., and Byrne, B. A. (2015). Pathogenesis of Streptococcus infantarius subspecies coli isolated from sea otters with infective Endocarditis. Comp. Immunol. Microbiol. Infect. Dis. 40, 7-17. doi: 10.1016/j.cimid.2015.03.002

Counihan-Edgar, K. L., Gill, V. A., Doroff, A. M., Burek, K. A., Miller, W. A., Shewmaker, P. L., et al. (2012). Genotypic characterization of Streptococcus infantarius subsp. coli isolates from sea otters with infective endocarditis and/or septicemia and from environmental mussel samples. J. Clin. Microbiol. 50, 4131-4133. doi: $10.1128 / \mathrm{jcm} .02581-12$

DeGange, A. R., and Vacca, M. M. (1989). Sea otter mortality at Kodiak Island, Alaska, during summer 1987. J. Mammal. 70, 836-838. doi: 10.2307/1381723

Diener, M., Erler, K., Christian, B., and Luckas, B. (2007). Application of a new zwitterionic hydrophilic interaction chromatography column for determination of paralytic shellfish poisoning toxins. J. Sep. Sci. 30, 1821-1826. doi: $10.1002 /$ jssc. 200700025

Dierauf, L., and Gulland, F. M. (2001). CRC Handbook of Marine Mammal Medicine: Health, Disease, and Rehabilitation. Boca Raton, FL: CRC press.

Doroff, A., and Badajos, O. (2010). "Monitoring survival and movement patterns of sea otters (Enhydra lutris kenyoni) in Kachemak Bay, Alaska, August 2007-April 2010: final report," in Kachemak Bay Research Reserve, ed. M. M. Management, (Anchorage, AK: USFWS).

Duncan, C., Gill, V. A., Worman, K., Burek-Huntington, K., Pabilonia, K. L., Johnson, S., et al. (2015). Coxiella burnetii exposure in northern sea otters Enhydra lutris kenyoni. Dis. Aquat. Organ. 114, 83-87. doi: 10.3354/dao02857

Fisher, R. A. (1935). The logic of inductive inference. J. R. Stat. Soc. Ser. 98, 39-54. doi: 10.1111/j.2397-2335.1935.tb04208.x

Garlich-Miller, J., Esslinger, G. G., and Weitzman, B. (2018). Aerial Surveys of Sea Otters (Enhydra lutris) in Lower Cook Inlet, Alaska, May, 2017. Anchorage, AK: US Fish and Wildlife Service.

Garshelis, D. L., Johnson, A. M., and Garshelis, J. A. (1984). Social organization of sea otters in Prince William Sound. Alaska. Can. J. Zool. 62, 2648-2658. doi: $10.1139 / \mathrm{z} 84-385$

Gill, V. A., Doroff, A., and Burn, D. M. (2009). Aerial Surveys of Sea Otters (Enhydra lutris) in Kachemak Bay, Alaska, 2008. Anchorage, AK: US Fish and Wildlife Service.
Goertz, C. E., Walton, R., Rouse, N., Belovarac, J., Burek-Huntington, K., Gill, V., et al. (2013). "Vibrio parahaemolyticus, a climate change indicator in Alaska Marine Mammals," in Responses of Arctic Marine Ecosystems to Climate Change. Alaska, eds F. Meuter, D. Dickson, H. P. Huntington, J. Irvine, E. Logerwell, S. MacLean, et al. (Fairbanks, AK: Alaska Sea Grant, University of Alaska Fairbanks).

Goldstein, T., Gill, V. A., Tuomi, P., Monson, D., Burdin, A., Conrad, P. A., et al. (2011). Assessment of clinical pathology and pathogen exposure in sea otters (Enhydra lutris) bordering the threatened population in Alaska. J. Wildl. Dis 47, 579-592. doi: 10.7589/0090-3558-47.3.579

Goldstein, T., Johnson, S., Phillips, A., Hanni, K., and Fauquicr, D. (1999). Humanrelated injuries observed in live stranded pinnipeds along the. Aquat. Anim. 25, $43-51$.

Goldstein, T., Mazet, J. K., Gill, V. A., Doroff, A. M., Burek, K. A., and Hammond, J. A. (2009). Phocine distemper virus in northern sea otters in the Pacific Ocean, Alaska, USA. Emerg. Infect. Dis. 15, 925-927. doi: 10.3201/eid1506.090056

Gorbics, C., and Bodkin, J. L. (2001). Stock structure of sea otters (Enhydra lutris kenyoni) in Alaska. Mar. Mamm. Sci. 17, 632-647. doi: 10.1111/j.1748-7692. 2001.tb01009.x

Hanni, K. D., Mazet, J. A. K., Gulland, F. M. D., Estes, J., Staedler, M., Murray, M. J., et al. (2003). Clinical pathology and assessment of pathogen exposure in southern and Alaskan sea otters. J. Wildl. Dis 39, 837-850. doi: 10.7589/00903558-39.4.837

Harley, J. R., Gill, V. A., Lee, S., Kannan, K., Santana, V., Burek-Huntington, K., et al. (2019). Concentrations of organohalogens (PCBs, DDTs, PBDEs) in hunted and stranded Northern sea otters (Enhydra lutris kenyoni) in Alaska from 1992 to 2010: links to pathology and feeding ecology. Sci. Total Environ. 691, 789-798. doi: 10.1016/j.scitotenv.2019.07.040

Hart, K., Gill, V. A., and Kannan, K. (2009). Temporal trends (1992-2007) of perfluorinated chemicals in northern sea otters (Enhydra lutris kenyoni) from South-Central Alaska. Arch. Environ Contam. Toxicol. 56, 607. doi: 10.1007/ s00244-008-9242-2

Hatfield, B. B., Yee, J. L., Kenner, M. C., and Tomoleoni, J. A. (2019). California Sea Otter (Enhydra Lutris Nereis) Census Results, Spring 2019. Reston, VA: U.S. Geological Survey, 12.

Herrero, I. A., Rouse, M. S., Piper, K. E., Alyaseen, S. A., Steckelberg, J. M., and Patel, R. (2002). Reevaluation of Streptococcus bovis endocarditis cases from 1975 to 1985 by 16 S ribosomal DNA sequence analysis. J. Clin. Micro. 40, 3848-3850. doi: $10.1128 / \mathrm{jcm} .40 .10 .3848-3850.2002$

Hooper, P., Zaki, S., Daniels, P., and Middleton, D. (2001). Comparative pathology of the diseases caused by Hendra and Nipah viruses. Microbes Infect. 3, 315-322. doi: 10.1016/s1286-4579(01)01385-5

Hoyt, Z., Eckert, G., Gill, V., and Rice, A. (2014). "Sea otter recolonization and interactions with commercially important macroinvertebrates in Southeast Alaska," in North Pacific Research Board Final Report (Anchorage, AK: North Pacific Research Board).

Jessup, D. A., Miller, M. A., Kreuder-Johnson, C., Conrad, P. A., Tinker, M. T., Estes, J., et al. (2007). Sea otters in a dirty ocean. J. Am. Vet. Med. Assoc. 231, 1648-1652. doi: 10.2460/javma.231.11.1648

Joly, D. O., Heisey, D. M., Samuel, M. D., Ribic, C. A., Thomas, N. J., Wright, S. D., et al. (2009). Estimating cause-specific mortality rates using recovered carcasses. J. Wildl. Dis. 45, 122-127. doi: 10.7589/0090-3558-45. 1.122

Joseph, B. E., Spraker, T. R., and Migaki, G. (1990). Valvular endocarditis in a northern sea otter (Enhydra lutris). J. Zoo Wildl. Med. 21, 88-91.

Kenyon, K. W. (1969). The sea otter in the Eastern Pacific Ocean. N. Am. Fauna 68, 1-352. doi: 10.3996/nafa.68.0001

Kreuder, C., Miller, M. A., Jessup, D. A., Lowenstine, L. J., Harris, M. D., Ames, J., et al. (2003). Patterns of mortality in southern sea otters (Enhydra lutris nereis) from 1998-2001. J. Wildl. Dis. 39, 495-509. doi: 10.7589/0090-3558-39.3.495

Kreuder, C., Miller, M. A., Lowenstine, L. J., Conrad, P. A., Carpenter, T. E., Jessup, D. A., et al. (2005). Evaluation of cardiac lesions and risk factors associated with myocarditis and dilated cardiomyopathy in southern sea otters (Enhydra lutris nereis). Am. J. Vet. Res. 66, 289-299. doi: 10.2460/ajvr.2005.66.289

Kvitek, R., and Bretz, C. (2004). Harmful algal bloom toxins protect bivalve populations from sea otter predation. Mar. Ecol. Prog. Ser. 271, 233-243. doi: $10.3354 /$ meps271233

Lefebvre, K. A., Quakenbush, L., Frame, E., Burek Huntington, K., Sheffield, G., Stimmelmayr, R., et al. (2016). Prevalence of algal toxins in Alaskan marine 
mammals foraging in a changing arctic and subarctic environment. Harmful Algae 55, 13-24. doi: 10.1016/j.hal.2016.01.007

Lepidi, H., Fournier, P. E., and Raoult, D. (2000). Quantitative analysis of valvular lesions during Bartonella endocarditis. Am. J. Clin. Path. 114, 880. doi: 10.1309/ r0kq-823a-btc7-muuj

Lewitus, A. J., Horner, R. A., Caron, D. A., Garcia-Mendoza, E., Hickey, B. M., Hunter, M., et al. (2012). Harmful algal blooms along the North American west coast region: history, trends, causes, and impacts. Harmful Algae 19, 133-159. doi: 10.1016/j.hal.2012.06.009

Lipscomb, T. P., Harris, R. K., Rebar, A. H., Ballachey, B. E., and Haebler, R. J. (2013). "Pathology of sea otters," in Marine Mammals and the Exxon Valdez, ed. T. R. Loughlin, (San Diego: Academic Press), 1994.

Miles, A. K., Bowen, L., Ballachey, B., Bodkin, J. L., Murray, M., Estes, J., et al. (2012). Variations of transcript profiles between sea otters Enhydra lutris from Prince William Sound, Alaska, and clinically normal reference otters. Mar. Ecol. Prog. Ser. 451, 201-212. doi: 10.3354/meps09572

Miller, M., Gardner, I., Kreuder, C., Paradies, D., Worcester, K., Jessup, D., et al. (2002a). Coastal freshwater runoff is a risk factor for Toxoplasma gondii infection of southern sea otters (Enhydra lutris nereis). Int. J. Parasit. 32, 997-1006. doi: 10.1016/s0020-7519(02)00069-3

Miller, M., Grigg, M., Kreuder, C., James, E., Melli, A., Crosbie, P., et al. (2004). An unusual genotype of Toxoplasma gondii is common in California sea otters (Enhydra lutris nereis) and is a cause of mortality. Int. J. Parasit. 34, 275-284. doi: 10.1016/j.ijpara.2003.12.008

Miller, M. A., Byrne, B. A., Jang, S. S., Dodd, E. M., Dorfmeier, E., Harris, M. D., et al. (2010a). Enteric bacterial pathogen detection in southern sea otters (Enhydra lutris nereis) is associated with coastal urbanization and freshwater runoff. Vet. Res. 41, 1-13.

Miller, M. A., Conrad, P. A., Harris, M., Hatfield, B., Langlois, G., Jessup, D. A., et al. (2010b). A protozoal-associated epizootic impacting marine wildlife: mass-mortality of southern sea otters (Enhydra lutris nereis) due to Sarcocystis neurona infection. Vet. Parasitol. 172, 183-194. doi: 10.1016/j.vetpar.2010.05. 019

Miller, M. A., Duignan, P. J., Dodd, R., Batac, F., Staedler, M., Tomoleni, J. A., et al. (2020). Emergence of a zoonotic pathogen in a coastal marine sentinel: Capillaria hepatica (syn. Calodium hepaticum), associated Hepatitis in southern sea otters (Enhydra lutris nereis). Front. Mar. Sci. 7:335. doi: 10.3389/fmars. 2020.00335

Miller, M. A., Gardner, I. A., Packham, A., Mazet, J. K., Hanni, K. D., Jessup, D., et al. (2002b). Evaluation of an indirect fluorescent antibody test (IFAT) for demonstration of antibodies to Toxoplasma gondii in the sea otter (Enhydra lutris). J. Parasitol. 88, 594-599. doi: 10.2307/3285456

Monson, D. H., Doak, D. F., Ballachey, B. E., Johnson, A., and Bodkin, J. L. (2000). Long-term impacts of the Exxon Valdez oil spill on sea otters, assessed through age-dependent mortality patterns. Proc. Natl. Acad. Sci. U.S.A. 97, 6562-6567. doi: 10.1073/pnas.120163397

Morkill, A. (2005). "Shipwrecks, spills, and seabirds: wildlife at risk on the Alaska Maritime National Wildlife Refuge," in The Selendang Ayu Oil Spill: Lessons Learned, Conference Proceedings, ed. R. S. Brewer, (Fairbanks, AK: Alaska Sea Grant College Program), 19-32.

Pedersen, K., Jørgensen, J., Dietz, H.-H., and Andersen, T. (2003). Verrucous endocarditis associated with Streptococcus bovis in mink (Mustela vison). Vet. Rec. 153, 264-268. doi: 10.1136/vr.153.9.264

Pesavento, P. A., Chomel, B. B., Kasten, R. W., McDonald, K. A., and Mohr, F. C. (2005). Pathology of Bartonella endocarditis in six dogs. Vet. Pathol. 42, 370-373. doi: 10.1354/vp.42-3-370

RaLonde, R., and Wright, B. (2011). "Using blue mussels as an indicator species for testing domoic acid toxicity in subsistence bivalve harvest," in North Pacific Research Board Project (Anchorage, AK: North Pacific Research Board).

Riedman, M., and Estes, J. A. (1990). "The sea otter (Enhydra lutris): behavior, ecology, and natural history," in Biological Report (USA). No. 90 (14) (Washington, DC: U. S. F. W. Service).

Shen, Z., Batac, F., Mannion, A., Miller, M. A., Bakthavatchalu, V., Ho, C., et al. (2017). Novel urease-negative Helicobacter sp. 'H. enhydrae sp. nov.' isolated from inflamed gastric tissue of southern sea otters. Dis. Aquat. Organ. 123, 1-11. doi: 10.3354/dao03082
Simeone, C. A., Gulland, F. M., Norris, T., and Rowles, T. K. (2015). A systematic review of changes in marine mammal health in North America, 1972-2012: the need for a novel integrated approach. PLoS One 10:e0142105. doi: 10.1371/ journal.pone.0142105

Siqueira, J. D., Ng, T. F., Miller, M., Li, L., Deng, X., Dodd, E., et al. (2017). Endemic infection of stranded southern sea otters (Enhydra lutris nereis) with novel parvovirus, polyomavirus, and adenovirus. J. Wildl. Dis. 53, 532-542. doi: 10.7589/2016-04-082

Spellerberg, B., and Brandt, C. (2011). "Streptococcus," in. Manual of Clinical Microbiology, 10th Edn., eds J. Versalovic, K. C. Carroll, G. Funke, J. H. Jorgensen, M. L. Landry, and D. W. Warnock (Washington, DC: ASM Press), 331-349.

Thometz, N. M., Tinker, M. T., Staedler, M. M., Mayer, K. A., and Williams, T. M. (2014). Energetic demands of immature sea otters from birth to weaning implications for maternal costs, reproductive behavior and population-level trends. J. Exp. Biol. 217, 2053-2061. doi: 10.1242/jeb.099739

Tinker, M. T., Hatfield, B. B., Harris, M. D., and Ames, J. A. (2016). Dramatic increase in sea otter mortality from white sharks in California. Mar. Mamm. Sci. 32, 309-326. doi: 10.1111/mms.12261

Tobin, E. D., Wallace, C. L., Crumpton, C., Johnson, G., and Eckert, G. L. (2019). Environmental drivers of paralytic shellfish toxin producing Alexandrium catenella blooms in a fjord system of northern Southeast Alaska. Harmful Algae 88:101659. doi: 10.1016/j.hal.2019.101659

Tor, E. R., Puschner, B., and Whitehead, W. E. (2003). Rapid determination of domoic acid in serum and urine by liquid chromatography - electrospray tandem mass spectrometry. J. Agric. Food Chem. 51, 1791-1796. doi: 10.1021/ jf020947f

Tuomi, P., Burek, K., Wallace, C., and Fleetwood, M. (2006)."Highly metastatic neoplasia in two northern sea otters (Enhydra lutris kenyoni) from Kachemak Bay, Alaska," in Proceedings of the 37th Annual Conference of the International Association for Aquatic Animal Medicine (Nassau: William Van Bonn).

VanWormer, E., Carpenter, T. E., Singh, P., Shapiro, K., Wallender, W. W., Conrad, P. A., et al. (2016). Coastal development and precipitation drive pathogen flow from land to sea: evidence from a Toxoplasma gondii and felid host system. Sci. Rep. 6:29252.

VanWormer, E., Mazet, J., Hall, A., Gill, V., Boveng, P., London, J., et al. (2019). Viral emergence in marine mammals in the North Pacific may be linked to Arctic sea ice reduction. Sci. Rep. 9:15569.

Verma, S. K., Knowles, S., Cerqueira-Cézar, C. K., Kwok, O. C., Jiang, T., Su, C., et al. (2018). An update on Toxoplasma gondii infections in northern sea otters (Enhydra lutris kenyoni) from Washington State, USA. Vet. Parasitol. 258, 133-137. doi: 10.1016/j.vetpar.2018.05.011

von Biela, V. R., Gill, V. A., Bodkin, J. L., and Burns, J. M. (2009). Phenotypic plasticity in age at first reproduction of female northern sea otters (Enhydra lutris kenyoni). J. Mammal. 90, 1224-1231. doi: 10.1644/08-mamm-a-379.1

White, C. L., Lankau, E. W., Lynch, D., Knowles, S., Schuler, K. L., Dubey, J. P., et al. (2018). Mortality trends in northern sea otters (Enhydra lutris kenyoni) collected from the coasts of Washington and Oregon, USA (2002-15). J. Wildl. Dis. 54, 238-247. doi: 10.7589/2017-05-122

Zabka, T. S., Goldstein, T., Cross, C., Mueller, R. W., Kreuder-Johnson, C., Gill, S., et al. (2009). Characterization of a degenerative cardiomyopathy associated with domoic acid toxicity in California sea lions (Zalophus californianus). Vet. Pathol. 46, 105-119. doi: 10.1354/vp.46-1-105

Conflict of Interest: The authors declare that the research was conducted in the absence of any commercial or financial relationships that could be construed as a potential conflict of interest.

Copyright (C) 2021 Burek Huntington, Gill, Berrian, Goldstein, Tuomi, Byrne, Worman and Mazet. This is an open-access article distributed under the terms of the Creative Commons Attribution License (CC BY). The use, distribution or reproduction in other forums is permitted, provided the original author(s) and the copyright owner(s) are credited and that the original publication in this journal is cited, in accordance with accepted academic practice. No use, distribution or reproduction is permitted which does not comply with these terms. 